\title{
DEMYSTIFYING AND UNRAVELLING THE FACTUAL MOLECULAR STRUCTURE OF THE BIOPOLYMER SPOROPOLLENIN
}

Abanoub Mikhael, ${ }^{1}$ Kristina Jurcic, ${ }^{2}$ Celine Schneider, ${ }^{3}$ David Karr, ${ }^{4}$ Gregory L. Fisher, ${ }^{4}$ Travis D. Fridgen, ${ }^{1}$ Alberto Diego-Taboada, ${ }^{5}$ Grahame Mackenzie, ${ }^{5}$ and Joseph Banoub ${ }^{* 1,6}$

${ }^{1}$ Chemistry Department, Memorial University, St John's, 283 Prince Philip Dr, St John's, NL A1B 3X7, Canada

${ }^{2}$ MALDI Mass Spectrometry Facility, Western University, Department of Biochemistry, Medical Sciences Building 392, London, Ontario, Canada, N6A 5C1

${ }^{3}$ NMR Facility, C-CART/CREAIT network, Memorial University, St John's, 283 Prince Philip Dr, St John's, NL, A1B 3X7, Canada

${ }^{4}$ Physical Electronics, Inc. (PHI) 18725 Lake Drive East, Chanhassen, MN 55317, USA

${ }^{5}$ Department of Chemistry, University of Hull, Kingston upon Hull, HU6 7RX, UK

${ }^{6}$ Fisheries and Oceans Canada, Science Branch, Special Projects, 80 East White Hills Road, St John's, NL A1C 5X1, Canada

\begin{abstract}
Sporopollenin is a natural, highly cross-linked biopolymer composed of carbon, hydrogen, and oxygen, which forms the outer wall of pollen grains. Sporopollenin is resilient to chemical degradation. Because of this stability, its exact chemical structure and the biochemical pathways involved in its biosynthesis remains a mystery and unresolved.

We have identified and characterized the molecular structure of the clean, intact sporopollenin using soft ionization mass spectrometric and nuclear magnetic resonance techniques. These analyses showed that sporopollenin contained a poly(hydroxyacid) dendrimerlike network, which accounted for the sporopollenin empirical formula. In addition, the identified hydroxy acid monomers contained a beta diketone moiety, which most probably accounts for the known antioxidant activity of sporopollenin. Moreover, our elucidation studies allowed us to identify a unique circular polyhydroxylated tetraketide polymer. This polymer acted as the rigid backbone on which the poly(hydroxyacid) network can be built, forming the scaffold of the spherical sporopollenin exine
\end{abstract}




\section{INTRODUCTION}

The shells of the plant spores are natural microcapsules, which have progressed to protect the reproductive pollen of plants from air and light. ${ }^{[1]}$ The shells are formed from two attached layers; the outer shell is called the sporopollenin (exine), which is mainly lipophilic, and the inner shell (intine) is mainly composed of cellulose. ${ }^{[1]}$

Sporopollenin was generally designated as "one of the most exceptionally resistant materials knows in the organic world." ${ }^{[2]}$ Sporopollenin composition was defined to be a highly cross-linked polymer composed of carbon, hydrogen, and oxygen. ${ }^{[2]}$ It is highly resilient to chemical degradation, which is why its exact chemical structure and the biochemical pathways involved in its synthesis are not yet clear. ${ }^{[2]}$

Sporopollenin was suggested to be composed of varied and complex straight and branched aliphatic chains, some of which are saturated, unsaturated, and polyhydroxylated. ${ }^{[3]}$ Other suggested building blocks appeared to involve oxygenated aromatic rings and phenylpropanoid moieties. ${ }^{[2]}$ The cross-linking of these straight- and branched- aliphatic chains was tentatively described as either ether cross-linking and/or carbon-carbon bonds. ${ }^{[3,4]}$ Gordon Shaw et al. ${ }^{[5]}$, one of the earlier pioneers studying the structure of sporopollenin, indicated that the UV properties of sporopollenin were attributed to their similarities to polycarotene. Also, it was proposed by Hayatsu et al. ${ }^{[6]}$ that sporopollenin may be composed of a highly cross-linked network of lipids fatty acids and/or alcohols contradicting the proposal that sporopollenin exine was a carotenoid derivative. To keep it short, we can summarize the main trials to investigate the structure of sporopollenin into three major ideas. The sporopollenin exine can be constructed completely by an aliphatic biopolymer, or it can be completely built as an aromatic biopolymer, and finally it was proposed to exist as a mixture of aliphatic and aromatic biopolymer. ${ }^{[7-9]}$

It is very important to point out that the combustion of different sporopollenins under inert atmosphere (pyrolysis), coupled with electron ionization mass spectrometry has consistently yielded $p$-coumaric acid and/ or aromatic compounds that apparently, represented the major building block of sporopollenin. ${ }^{[10,11]}$ However, it is well known that pyrolysis can change the structure of the original material, especially when containing long aliphatic chains that can aromatize and produce aromatic compounds that originally did not exist and, even linear saturated polymers such as polyethylene can produce aromatics during pyrolysis GC-MS analysis. ${ }^{[12,13]}$ So, based on those outdated and old studies contingent on Pyrolysis GC-EI-MS, there is still a belief 
that sporopollenin contains aromatic compounds identified either as $p$-coumaric acid and/or to a lesser extent, ferulic acid. ${ }^{[10,11,14,15]}$. Moreover, Bernard et al. ${ }^{[16]}$ studied the thermal degradation of sporopollenin and realized that this occurred in two main stages. The first one below $500{ }^{\circ} \mathrm{C}$, where sporopollenin undergoes simultaneous dehydrogenation and deoxygenation. The second stage above $500^{\circ} \mathrm{C}$, where aromatic products are formed. This study shows that high-temperature pyrolysis can produce aromatic compounds that lead to blatantly misleading errors in the structure elucidation of sporopollenin. Another main detail from the Bernard study ${ }^{[16]}$ is that deoxygenation occurs mainly by the loss of $\mathrm{CO}_{2}$, supporting the hypothesis of Hayatsu et al ${ }^{[6]}$ who proposed that sporopollenin may be composed of a lipid network of fatty acids.

Recently, the group of Li et al. ${ }^{[15]}$ reported that by using a recent adoption of high-energy ball-milling and a newly developed thioacidolysis degradative method together with state-of-theart solid-state NMR techniques, they proposed a detailed molecular structure of pine pollen grain. These authors have indicated that the so-called degraded sporopollenin exine derived from the intact pine spore was primarily composed of aliphatic hydroxylated polyketides, aromatic moieties, and acetal groups as a cross-linker.

Nevertheless, it is important to note that synthetic organic chemistry uses extensively ball milling for the synthesis of new compounds. ${ }^{[17]}$ On the other hand, it is well known that ball milling of complex natural materials such as lignin and pollen grains can lead to alteration of their original structure and may produce new compounds that originally do not exist. ${ }^{[18]}$ For example, Milled wood Lignin (MWL) contains more hydroxyl groups than the native one due to the extensive depolymerization during the ball milling process. ${ }^{[18]}$ The presence of more hydroxyl groups indicated the homolytic bond cleavage between lignin monomers, which in turn produce reactive radicals that can create new compounds. ${ }^{[18]}$

The biosynthesis studies aiming to discover the exact molecular structure of sporopollenin have revealed an inkling about the major constituents of sporopollenin. Some studies reveal that polyhydroxylated ketide is one of the important sporopollenin monomers. ${ }^{[19,20]}$ The polyhydroxylated ketides are composed of the $\alpha$-pyrone ring with a hydroxylated aliphatic chain. It has been proposed that these polyhydroxylated ketides, along with fatty alcohols and or fatty acids, may form the sporopollenin exine building blocks ${ }^{[21]}$. Also, it has been established that sporopollenin absorbs UV radiation in the range of (280-315) nm, which is typically the range of UV absorption of alpha pyrone rings. ${ }^{[22,23]}$ 
In this work, we present a different point of view concerning the molecular structure of the sporopollenin exine of lycopodium clavatum, which disagrees with the work of Li et al. ${ }^{[15]}$ on the structure of the so-called degraded pine sporopollenin exine (Please refer to SI-1).

We present herein; the top-down structural elucidation accomplished on Lycopodium clavatum. By using high energy collision TOF-SIMS-MS/MS and MALDI-TOF/TOF-CIDMS/MS, we identified two building units in the lycopodium clavatum sporopollenin molecular structure. The first one is the poly(hydroxyacid) dendrimer-like network containing beta-diketone moieties, which represent the Lycopodium Clavatum sporopollenin empirical formula. The second building unit is the rigid circular polyhydroxylated tetraketide backbone on which the poly(hydroxyacid) network is constructed, forming the sporopollenin biopolymer. In addition, 1D and 2D Solid-state ${ }^{1} \mathrm{H}$ - and ${ }^{13} \mathrm{C}-\mathrm{NMR}$ experiments were consistent with the main diagnostic resonances of all $\mathrm{H}$ - and $\mathrm{C}$-atoms constituting the proposed structure of sporopollenin exine. Finally, X-ray photoelectron spectroscopy indicates the absence of aromaticity in the Lycopodium clavatum sporopollenin.

\section{Results and Discussion}

The Lycopodium clavatum sporopollenin used in this investigation was extracted by the classical method of Zetzsche et al. ${ }^{[24]}$ method using hot acetone, potassium hydroxide, and phosphoric acid. This series of sequential treatments are required to extract the protein-free hollow intact and clean exine microcapsule. ${ }^{[25]}$ It is essential to note that in this manuscript, we used clean Lycopodium clavatum sporopollenin exines prepared by the original Zetzsche et al. method. ${ }^{[26]}$ Originally, these sporopollenin microcapsule exines were used for the encapsulation of a wide variety of compounds, including both polar (e.g. drugs, dyes, proteins, carbohydrates, and oligonucleotides) and non-polar products (e.g. oils and waxes). ${ }^{[26]}$

\section{TOF-SIMS and keV-CID MS/MS}

The TOF-SIMS tandem MS imaging (+ ion mode) of the sporopollenin showed the ions at $\mathrm{m} / \mathrm{z} 575$ and 603, these ions are characteristic for diacylglycerol (DAG) derivatives and assigned as $\left[\mathrm{C}_{16} \mathrm{H}_{25} \mathrm{O}_{4} \mathrm{C}_{3} \mathrm{H}_{6} \mathrm{OC}_{14} \mathrm{H}_{21} \mathrm{O}_{4}+\mathrm{H}-\mathrm{H}_{2} \mathrm{O}\right]^{+}$and $\left[\mathrm{C}_{16} \mathrm{H}_{25} \mathrm{O}_{4} \mathrm{C}_{3} \mathrm{H}_{6} \mathrm{OC}_{16} \mathrm{H}_{25} \mathrm{O}_{4}+\mathrm{H}_{-} \mathrm{H}_{2} \mathrm{O}\right]^{+}$, respectively (SI-figure 1a). The product ion scans of the precursor ions at $\mathrm{m} / \mathrm{z} 575$ and 603 shows the formation of the characteristic acylium ions at $m / z 237$ and 265 assigned as $\left[\mathrm{C}_{14} \mathrm{H}_{21} \mathrm{O}_{3}\right]^{+}$and $\left[\mathrm{C}_{16} \mathrm{H}_{25} \mathrm{O}_{3}\right]^{+}$, 
respectively (SI-figure $2 \mathrm{a} \& \mathrm{~b}$ ). These acylium product ions contain another two oxygen atoms on their chains, but each product ion eliminates only one water molecule. This indicates that one oxygen is present on their chains as a hydroxyl group, while the remaining oxygen exists most probably as a keto group that cannot lead to the loss of a second molecule of water from these acylium ions.

Moreover, the carboxylate anions corresponding to these acylium ions were detected in the negative ion mode TOF-SIMS-MS at $m / z 253$ and 281 assigned as $\left[\mathrm{C}_{14} \mathrm{H}_{22} \mathrm{O}_{4}-\mathrm{H}\right]^{-}$and $\left[\mathrm{C}_{16} \mathrm{H}_{26} \mathrm{O}_{4-}\right.$ $\mathrm{H}^{-}$, respectively (SI-figure 1b). The product ion scan of these carboxylate ions showed the loss of one water molecule confirming the presence of a hydroxyl group in the chain of these acids, as mentioned before (SI-figure $3 \mathrm{a} \& \mathrm{~b}$ ). A proposed fragmentation mechanism for these acids is shown in SI-Scheme 1. Overall, the fragmentation mechanism shown in SI-scheme1 suggests that these carboxylic acids contain a beta diketone moiety in which, one oxygen occurs as enol form (which is lost as a water molecule), whereas the other one exists as keto form (which cannot be lost as a water molecule). This structural pattern is favorable for the presence of a beta diketone structure (SI-figure 4), as it facilitates the formation of an intramolecular hydrogen bond that gives extra stability to these kinds of structures. ${ }^{[27]}$ This hydrogen bonding resembles the case of intramolecular hydrogen bond in tetrahydrocurcumin (THC) molecules. ${ }^{[28]} \mathrm{Also}$, it is essential to mention that the loss of one water molecule in the product ion scans of the precursor ions $\left[\mathrm{C}_{14} \mathrm{H}_{22} \mathrm{O}_{4}-\mathrm{H}\right]^{-}$and $\left[\mathrm{C}_{16} \mathrm{H}_{26} \mathrm{O}_{4}-\mathrm{H}\right]^{-}$at $\mathrm{m} / z 253$ and 281 resemble the CID-MS/MS of THCmonoglucuronoside deprotonated molecule $[\mathrm{M}-\mathrm{H}]^{-}$at $\mathrm{m} / \mathrm{z} 549$. This latter ion showed the loss of the carbohydrate moiety to yield THC product ion at $m / z 373$, which subsequently loses only one water molecule to yield the base peak of the secondary product ion at $\mathrm{m} / \mathrm{z} 355$. In fact this is exactly what happens in the case of our precursor ions at $m / z 253$ and 281. ${ }^{[28]}$

It should be noted that these identified fatty acids contain an extra terminal hydroxyl group in their original structures, which allows them to be attached to another fatty acid through ester bond formation producing the poly(hydroxyacid) network of sporopollenin exine. This fact was deduced, after performing the MALDI-TOF-MS (+ ion mode using CHCA as a matrix) of sporopollenin, and an ion at $m / z, 1643.9948$ was identified and assigned as $\left[\mathrm{C}_{89} \mathrm{H}_{142} \mathrm{O}_{27}+\mathrm{H}\right]^{+}$. This ion confirms that the fatty acids forming the poly(hydroxyacid) network contain three oxygens in their chains. This will be discussed again later in this manuscript in section 3.2 (figures $2 \mathrm{a} \& \mathrm{~b}$, 
and figure 3). Moreover, the chemical formulas of all other ions formed in the positive or negative ion mode TOF-SIMS-MS are shown on the spectra (SI-figure $1 \mathrm{a} \& \mathrm{~b}$ ).

\section{MALDI-TOF-MS and HIGH- ENERGY (1 Kev) CID-MS/MS}

\subsection{MALDI-TOF-MS (+ ion mode) and CID-MS/MS (DAN Matrix)}

After revealing the presence of fatty acids using TOF-SIMS, the extracted sporopollenin exine was analyzed by MALDI-TOF-MS (+ ion mode) using DAN as a matrix. The use of DAN as a matrix was chosen to enhance the discovery of poly(hydroxyacid) moieties as it is an excellent matrix for the identification of lipids. ${ }^{[29]}$ It showed a complex series of ions that were very closely related, indicating the presence of a very complex heterogeneous mixture (SI-figure $5 \mathrm{a} \& \mathrm{~b}$ ).

Furthermore, when measuring their Kendrick mass defect plot, we noticed the formation of a bundle of ions that were strictly related to each other's (SI-figure 6). ${ }^{[30]}$ This Kendrick mass defect plot displayed a series of ions that, in general, varied in the number of methylene groups (14 Da). This is demonstrated in the zoomed part of the MS and its Kendrick Plot in the range of $m / z$ 1300-1500 Da (SI-figure 5 a \& b, and SI-figure 6).

As an example, we assigned the radical cation at $m / z 1965.1278$ as $\left[\mathrm{C}_{106} \mathrm{H}_{164} \mathrm{O}_{33}\right]^{+\bullet}$ composed of two hydroxylated triglycerides (6 x C14) connected by an extra spacer (C16) hydroxylated carboxylic acid (Figure 1) and appears like a branching unit in triacylglycerol (TAG) dendrimers. ${ }^{[31]}$ Also, it should be noted that the formula of this ion at $m / z$ 1965.1278 fits very well with the empirical formula $\left[\mathrm{C}_{90} \mathrm{H}_{142} \mathrm{O}_{27}\right]$ of Lycopodium clavatum sporopollenin. Other ions chemical formulas are shown on the spectrum (SI-figure $5 \mathrm{a} \& \mathrm{~b}$ ).

As another example, we have assigned the ion at $m / z 1441.8037$ as $\left[\mathrm{C}_{81} \mathrm{H}_{132} \mathrm{O}_{21}+\mathrm{H}\right]^{+}$, and its molecular structure was supported by its proposed CID-MS/MS fragmentation pathways, as shown in SI-figure 7 and scheme 1. 


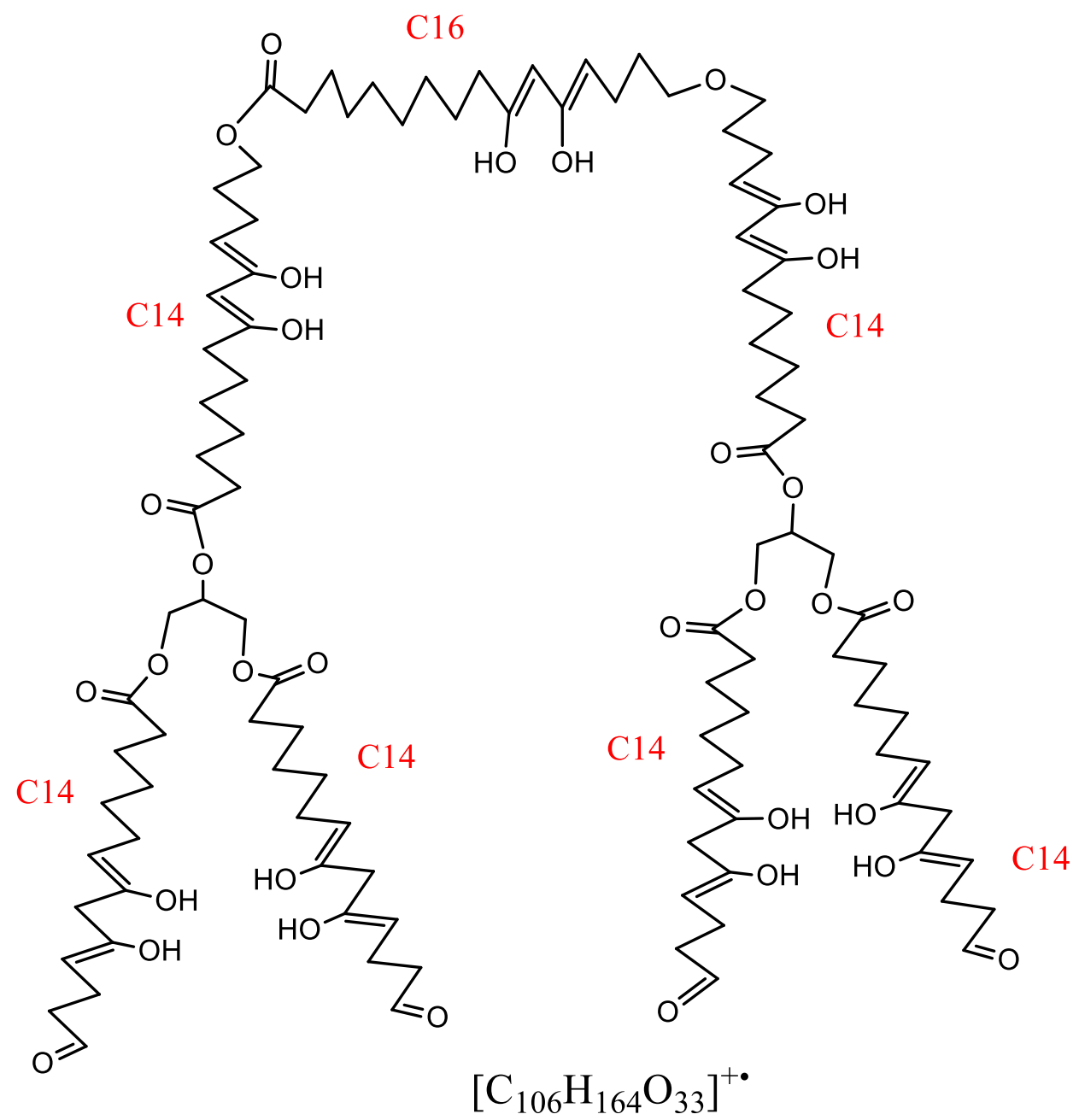

1965.12

Figure 1. The proposed structure of the poly(hydroxyacid) with glycerol as a core unit at $\mathrm{m} / \mathrm{z}$ 1965 identified in MALDI-MS using DAN as a matrix 


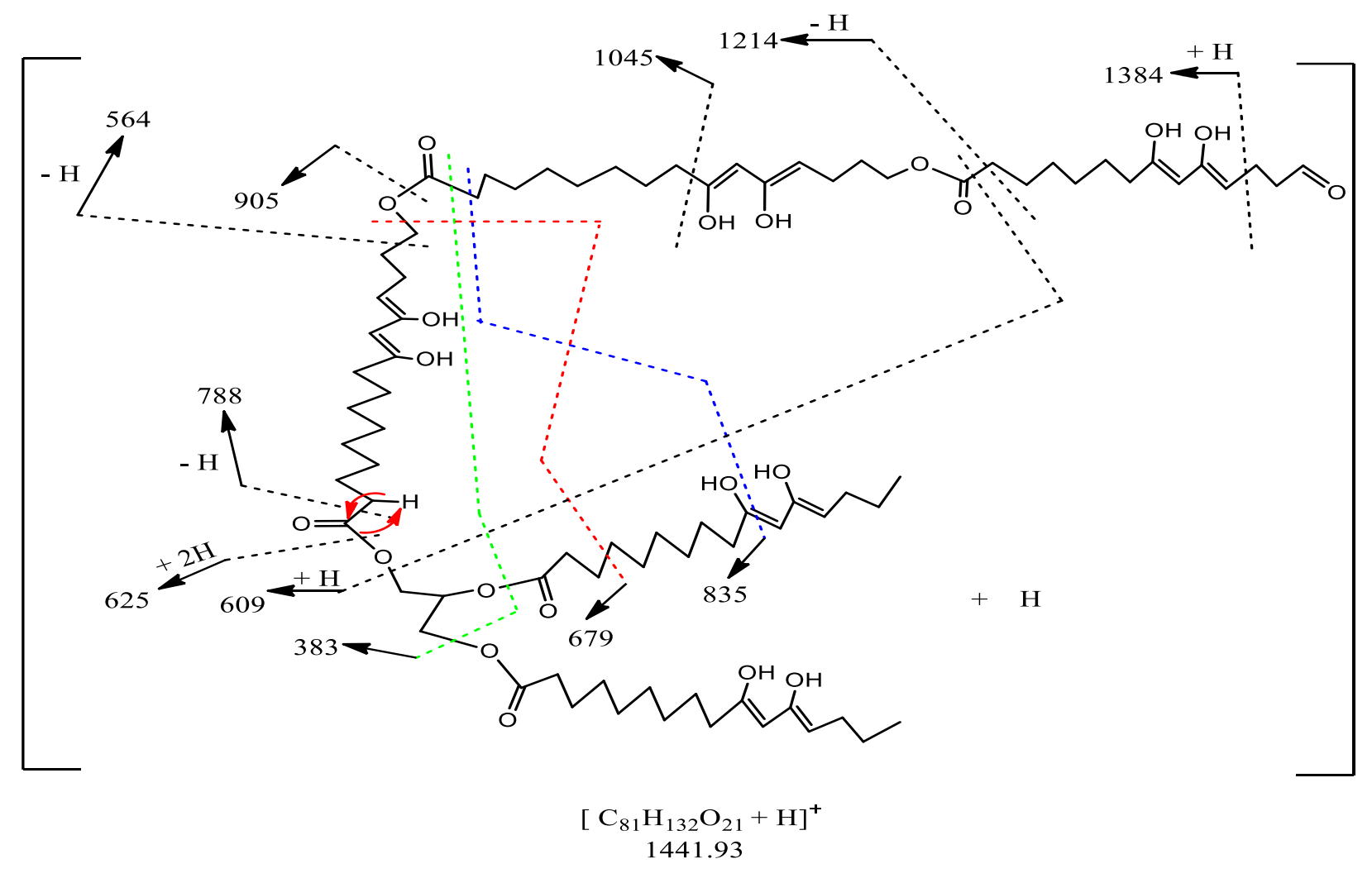

Scheme 1. Mechanism of the product ion scan of the precursor ion at $m / z 1441.93$ identified in Sporopollenin MALDI-MS using DAN as a matrix. Note: the product ion at $m / z 625$ is formed through ketene loss indicated by red arrows ${ }^{[32]}$.

\subsection{MALDI-TOF-MS (+ ion mode) using CHCA as a Matrix}

The sporopollenin MALDI-TOF-MS using CHCA as a matrix showed the presence of a heterogeneous mixture of higher molecular weight poly(hydroxyacid) than the ones obtained by DAN (Figure 2a and b). However, it should be noted that the mass region around $\mathrm{m} / z$ 100-1300 was mainly composed of CHCA matrix peaks, ${ }^{[33]}$ whereas the region from 1500 to $2500 \mathrm{Da}$ was composed of significant analyte ions. In the zoomed region from $\mathrm{m} / \mathrm{z} 1500$ to 1700 , we observed a series of ions that differ by $\mathrm{C}_{2} \mathrm{H}_{4}\left(2 \times \mathrm{CH}_{2}\right)$ in their structure (Figure $2 \mathrm{a}$ and $\mathrm{b}$ ). The most important one is the peak at $\mathrm{m} / z 1643.9948$ (mentioned before in the TOF-SIMS section), which was assigned as $\left[\mathrm{C}_{89} \mathrm{H}_{142} \mathrm{O}_{27}+\mathrm{H}\right]^{+}$. This assignment fair very well with the empirical formula of Lycopodium clavatum sporopollenin $\left(\mathrm{C}_{90} \mathrm{H}_{142} \mathrm{O}_{27}\right)$ calculated by Zetzsche et al. (Figure 5) ${ }^{[24]}$. This old information about the lycopodium clavatum sporopollenin empirical formula was the most useful information that helped us in the interpretation of the whole data in this manuscript. This 
ion was identified with good accuracy $(+4.9$ error ppm), and its chemical formula fits the experimental isotopic distribution pattern with $71.2 \%$.

With this new finding, we finally arrived in obtaining new clear evidence to support and characterize the ions which corresponded to the empirical formula $\mathrm{C}_{90} \mathrm{H}_{142} \mathrm{O}_{27}$ of sporopollenin extracted from Lycopodium clavatum (Figure 2a and b).

Another interesting region that is important to discuss is in the range of $m / z 2300$ to 2500, where we observed a series of ions that differed by $\mathrm{C}_{2} \mathrm{H}_{4}$ units in their structure. As an example from this region, we showed the proposed structure for the peaks at $m / z 2428.4433$ (TAG) assigned as $\left[\mathrm{C}_{133} \mathrm{H}_{207} \mathrm{O}_{39}\right]^{+}$containing nine fatty acids (seven trihydroxy $\mathrm{C} 14$ and two trihydroxy $\mathrm{C} 16$ ) plus glycerol as a core unit (Figure 3). It should be noted that the important ion at $m / z$ 1643.9948 (DAG) derived from $\mathrm{m} / \mathrm{z} 2428.4433$ (TAG), and it is composed of six fatty acids plus glycerol moiety (five trihydroxy C14 and one trihydroxy C16) (Figure 3). These proposed structures provide more support for the presence of poly(hydroxyacid) with glycerol as a core unit and show the structure of the smallest unit (empirical formula) of lycopodium clavatum sporopollenin.

To sum up sections 1, 2.1, and 2.2, we have identified a series of branched poly(hydroxyacid) with glycerol as a core unit, by using TOF-SIMS- and MALDI-TOF/TOFMS/MS. The poly(hydroxyacid) is composed mainly of various combinations of the C16 and C14, with three oxygen atoms substituted on their chains. These fatty acids contain one terminal hydroxyl group, and the other two hydroxyl groups exist in their chains as a beta-diketone moiety. This beta diketone moieties could help in understanding the antioxidant activity of sporopollenin exine. ${ }^{[2,34]}$ The structures of these branched poly(hydroxyacid) provide the first-ever report in the literature, showing the existence of a natural "Dendrimer" like molecule. 


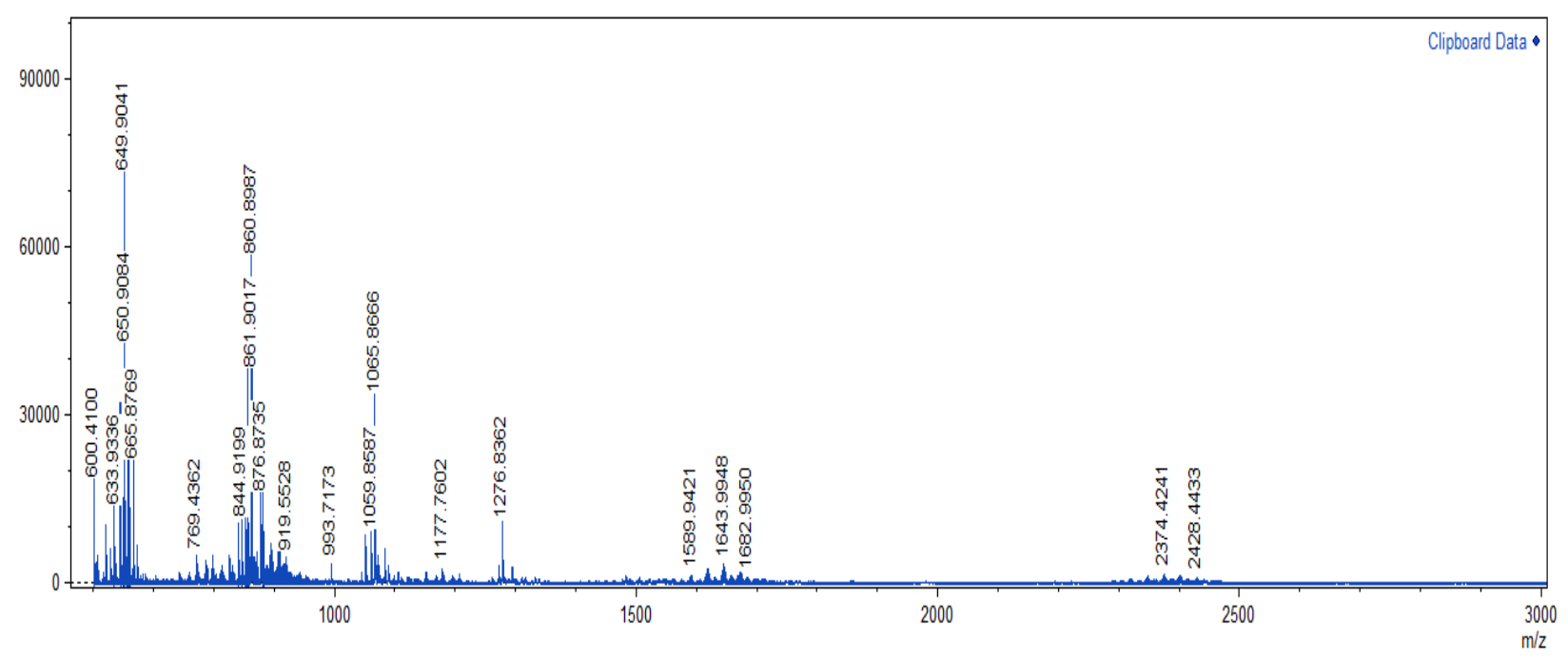

Figure 2a. MALDI-MS of sporopollenin using CHCA as a matrix

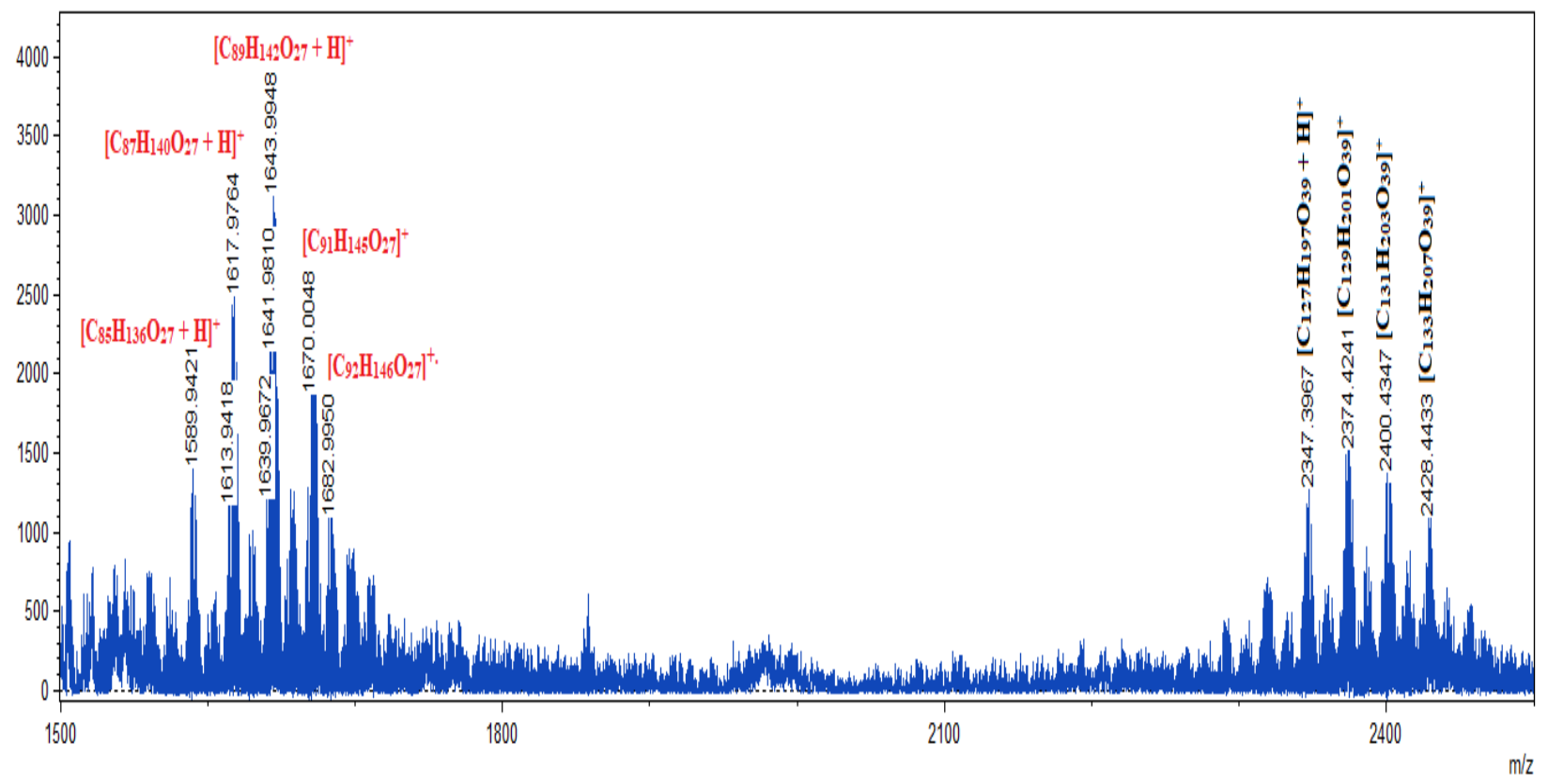

Figure 2b.(continued) Zooming of Sporopollenin MALDI-MS in the high mass region at $\mathrm{m} / \mathrm{z}$, 15003000 . 


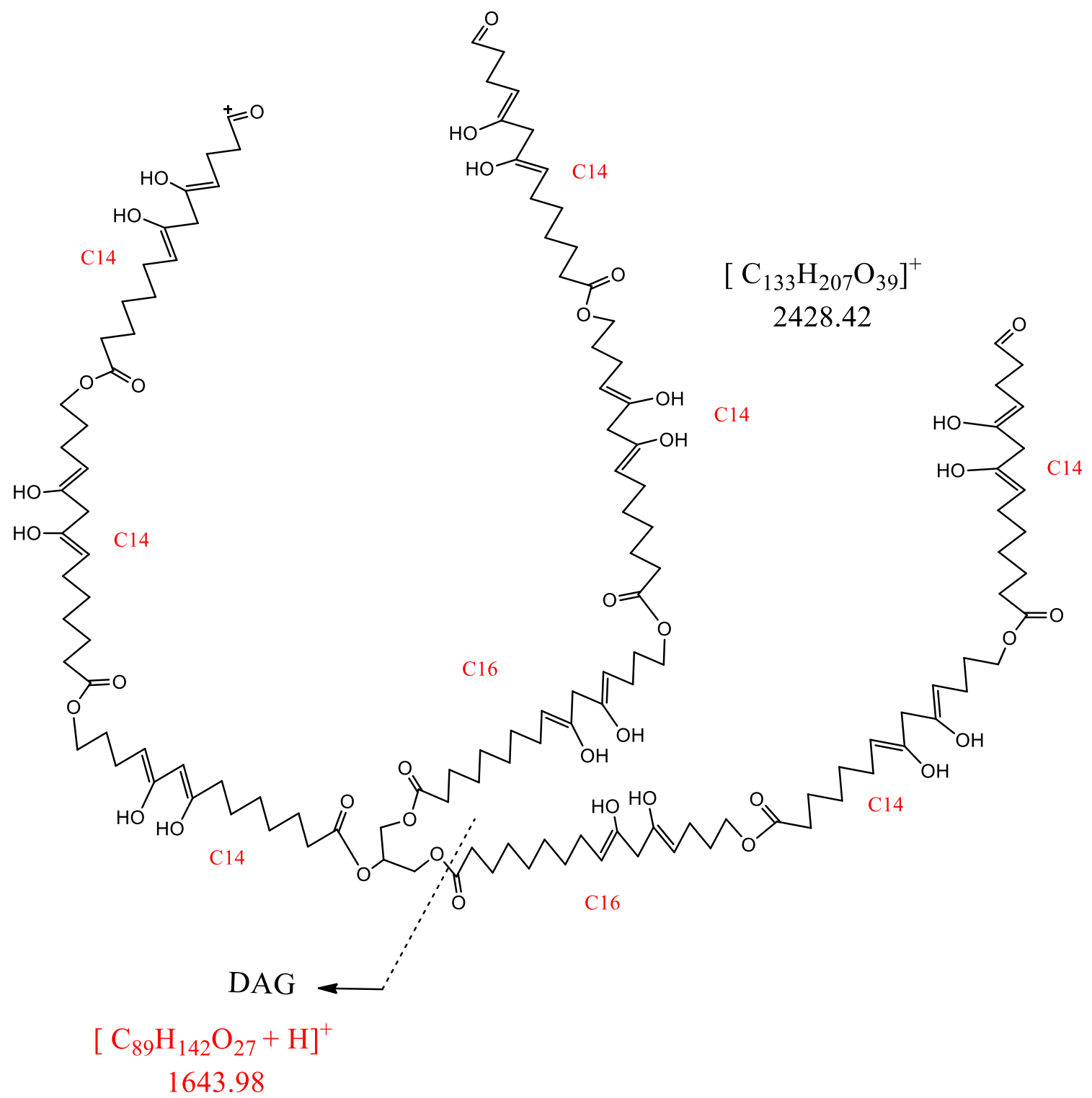

Figure 3. The proposed structure of $\mathrm{m} / z 2428.42$ and 1643.98 identified in sporopollenin MALDIMS using CHCA as a matrix

\subsection{MALDI-TOF-MS (+ion mode) and CID-MS/MS (HABA Matrix)}

MALDI-TOF-MS (+ ion mode) of the sporopollenin using HABA as a matrix showed a different MS pattern (polymer with a 280 Da repeating unit) than the one observed with either DAN or CHCA. Contrary to these two last matrices, the MALDI-MS with the HABA matrix gives new structural information about sporopollenin. A series of sodiated molecular ions containing both $\mathrm{Na}$ and $\mathrm{K}$ in their molecular formulae was observed using HABA as matrix. These ions at $m / z$ 1983.4810, 1703.4147, 1423.3455 and 1143.2730 were identified as $\left[\mathrm{C}_{94} \mathrm{H}_{91} \mathrm{KNa}_{2} \mathrm{O}_{41}+\mathrm{Na}\right]^{+}$, 
$\left[\mathrm{C}_{81} \mathrm{H}_{79} \mathrm{KNa}_{2} \mathrm{O}_{34}+\mathrm{Na}\right]^{+},\left[\mathrm{C}_{68} \mathrm{H}_{67} \mathrm{KNa}_{2} \mathrm{O}_{27}+\mathrm{Na}\right]^{+}$and $\left[\mathrm{C}_{55} \mathrm{H}_{55} \mathrm{KNa}_{2} \mathrm{O}_{20}+\mathrm{Na}\right]^{+}$, respectively (Figure 4). These four sodiated molecular ions differed from each other by a repeating unit of $280 \mathrm{Da}$ assigned as a polyhydroxylated tetraketide derivative with chemical formula $\mathrm{C}_{13} \mathrm{H}_{12} \mathrm{O}_{7}$. Please note that this series of sodiated molecular ions contained both $\mathrm{K}$ and $\mathrm{Na}$ carboxylates in their respective structures, and these were formed during the $\mathrm{KOH}$ step in the extraction process of sporopollenin from Lycopodium clavatum pollen grains plus the washing step at the end using $\mathrm{NaOH}$ as indicated in the experimental section. ${ }^{[35]}$ During this $\mathrm{KOH}$ treatment, proteins were removed, and ester bonds in its outer surface became partially hydrolyzed to carboxylic acid salts, and this increases sporopollenin hydrophilicity. ${ }^{[35]}$ Also, please note that these particularly small metal ions such as $\mathrm{K}^{+}$or $\mathrm{Na}^{+}$can originally enter this massive network of spherical sporopollenin via multidirectional nano-diameter sized channels easily. ${ }^{[2]}$ Moreover, the step after the base $(\mathrm{KOH})$ hydrolysis is acid hydrolysis using phosphoric acid. So, phosphoric acid may neutralize potassium carboxylate resulting from the first step, but actually, potassium is still there, as shown in the data presented in this section.

Moreover, we observed another series with almost the same chemical formulae, except, that the $\mathrm{K}$ atoms were replaced by $\mathrm{Na}(-16 \mathrm{Da})$, these ions were identified at $\mathrm{m} / \mathrm{z} 1687.4452$, 1407.3719 and 1127.2996 and assigned as $\left[\mathrm{C}_{81} \mathrm{H}_{79} \mathrm{Na}_{3} \mathrm{O}_{34}+\mathrm{Na}\right]^{+},\left[\mathrm{C}_{68} \mathrm{H}_{67} \mathrm{Na}_{3} \mathrm{O}_{27}+\mathrm{Na}\right]^{+}$and $\left[\mathrm{C}_{55} \mathrm{H}_{55} \mathrm{Na}_{3} \mathrm{O}_{20}+\mathrm{Na}\right]^{+}$(Figure 4).

Unexpectedly, the high-energy KeV CID-MS/MS of these precursor ions at $\mathrm{m} / \mathrm{z} 1983$, 1703, 1423 and 1143 showed a base peak formed by the loss of the repeating unit of $280 \mathrm{Da}$ (i.e., $\mathrm{m} / \mathrm{z} 1983$ produces $\mathrm{m} / \mathrm{z} 1703 ; \mathrm{m} / \mathrm{z} 1703$ produces $\mathrm{m} / \mathrm{z} 1423 ; \mathrm{m} / \mathrm{z} 1423$ produces $\mathrm{m} / \mathrm{z} 1143$ and finally $m / z 1143$ produces $m / z$ 863). For example, the product ion scan of the precursor ion at $m / z$ 1983 showed the sequential loss of $280 \mathrm{Da}(\mathrm{m} / \mathrm{z} 1983 \rightarrow \mathrm{m} / \mathrm{z} 1703 \rightarrow \mathrm{m} / \mathrm{z} 1423 \rightarrow \mathrm{m} / \mathrm{z}, 1143 \rightarrow \mathrm{m} / \mathrm{z}$ 863) (Figure 5 a \& b, and scheme 2).

It is evident from the MS/MS of the precursor ion at $m / z 1983$ afforded the product ion at $m / z 863$, which in turn produced the secondary product ion at $m / z 287$. This indicates that the first product ion at $m / z 863$ is composed of three attached units of the secondary product ion at $\mathrm{m} / \mathrm{z} 287$ $(3 \times 287 \mathrm{Da}+2 \mathrm{H}=863)$. Furthermore, the product ion scan fragmentation of this precursor ion is initiated by loss of $-\mathrm{CH}=\mathrm{CH}-\mathrm{CH}_{2}-\mathrm{CH}=\mathrm{CH}-(66 \mathrm{Da})$, which agrees with the presence of unsaturated fatty acids. Moreover, this product ion scan is not initiated by the loss of 44 Da supporting the 
absence of free carboxylic acid groups. Other CID-MS/MS fragmentation pathways that support the proposed structure of the precursor ion at $m / z, 1983$ are shown in scheme 2 .

To support our proposed structure of the precursor ion at $m / z 1983$ and its CID-MS/MS fragmentation patterns presented in scheme 2, we measured the quasi-MS ${ }^{3}$ spectrum of the product ion at $m / z$ 863. ${ }^{[36-38]}$ (SI-figure 8). The quasi-MS ${ }^{3}$ spectrum of the product ion at $m / z$ 863, showed the presence of both sodium and potassium atoms in the chemical composition of this product ion. It should be noted that the presence of both $\mathrm{Na}$ and $\mathrm{K}$ atoms in this ion, indeed, created a challenge in proposing a structure for this ion at $m / z 863$ (which is composed of three units of $m / z 287 \mathrm{Da}$ ); (Figure 5 a \& b). After examining series of rational structures, we have chosen the most tailored reasonable structure that agreed with the exact mass and the MS/MS of the original precursor ion at $m / z$ 1983, $\left[\mathrm{C}_{94} \mathrm{H}_{91} \mathrm{KNa}_{2} \mathrm{O}_{41}+\mathrm{Na}\right]^{+}$. Consequently, the product ions at $m / z, 863$ can be isobaric either $\left[\mathrm{C}_{42} \mathrm{H}_{43} \mathrm{KNa}_{2} \mathrm{O}_{13}+\mathrm{Na}\right]^{+}$or $\left[\mathrm{C}_{42} \mathrm{H}_{43} \mathrm{Na}_{3} \mathrm{O}_{13}+\mathrm{K}\right]^{+}$; and is composed of three tetraenoic $\mathrm{C} 14$ carboxylic acid derivatives. Furthermore, the quasi-MS ${ }^{3}$ of the product ion at $m / z 863$ showed the loss of carbon dioxide to give the $\left[\mathrm{M}+\mathrm{Na}-\mathrm{CO}_{2}\right]^{+}$product ion at $m / z 819$ and the formation of its corresponding $\left[\mathrm{M}+\mathrm{H}-\mathrm{CO}_{2}\right]^{+}$at $m / z 797$ (SI-figure 8). This quasi-MS ${ }^{3}$ fragmentation pattern supports the presence of the free carboxylic acid group in the structure of $\mathrm{m} / \mathrm{z} 863$, which was created after the cleavage of the cyclic oligomer at $\mathrm{m} / \mathrm{z}$ 1983. Other fragmentation patterns that support the structure of the product ion at $m / z 863$ are shown in scheme 3 .

It is important to note that the branched carboxylate salts may exist originally as cyclic esters that were hydrolyzed during the extraction process. Also, the presence of the double bonds may originally exist as shown in the structure of the product ion at $m / z 863$, or it can be formed by the dehydration of a hydroxylated chain, during the extraction process

It should be noted the molecular structures of this series of ions obtained in the MALDIMS using HABA as a matrix were identified with good mass accuracy (<25ppm). Similarly, we calculated the theoretical isotopic distribution of the chemical formula assigned to the highest intensity peak in the MS $(\mathrm{m} / \mathrm{z}$ 1127). The theoretical isotopic distribution of this peak showed excellent fitting with the experimental isotopic distribution (ca. 90\%, as shown in SI-figure 9).

In summary, the MALDI-TOF/TOF-MS/MS using HABA as a matrix showed the presence of a cyclic polyhydroxylated tetraketide repeating unit (alpha-pyrone ring plus hydroxylated aliphatic chain) that forms a cyclic polyhydroxylated tetraketide polymer backbone. The hydroxyl groups of this circular polymer can be attached to the terminal hydroxyl groups of the 
poly(hydroxyacid) network identified using DAN and CHCA matrices through ether linkages. Consequently, this cyclic polymer appears to act like the building stone on which the poly(hydroxyacid) network can be built, forming the scaffold of the spherical sporopollenin. Also, it is possible that sporopollenin wall consists of a dendrimer possessing alternative layers of polyhydroylated tetraketide cyclic polymer and poly(hydroxyacid) network.

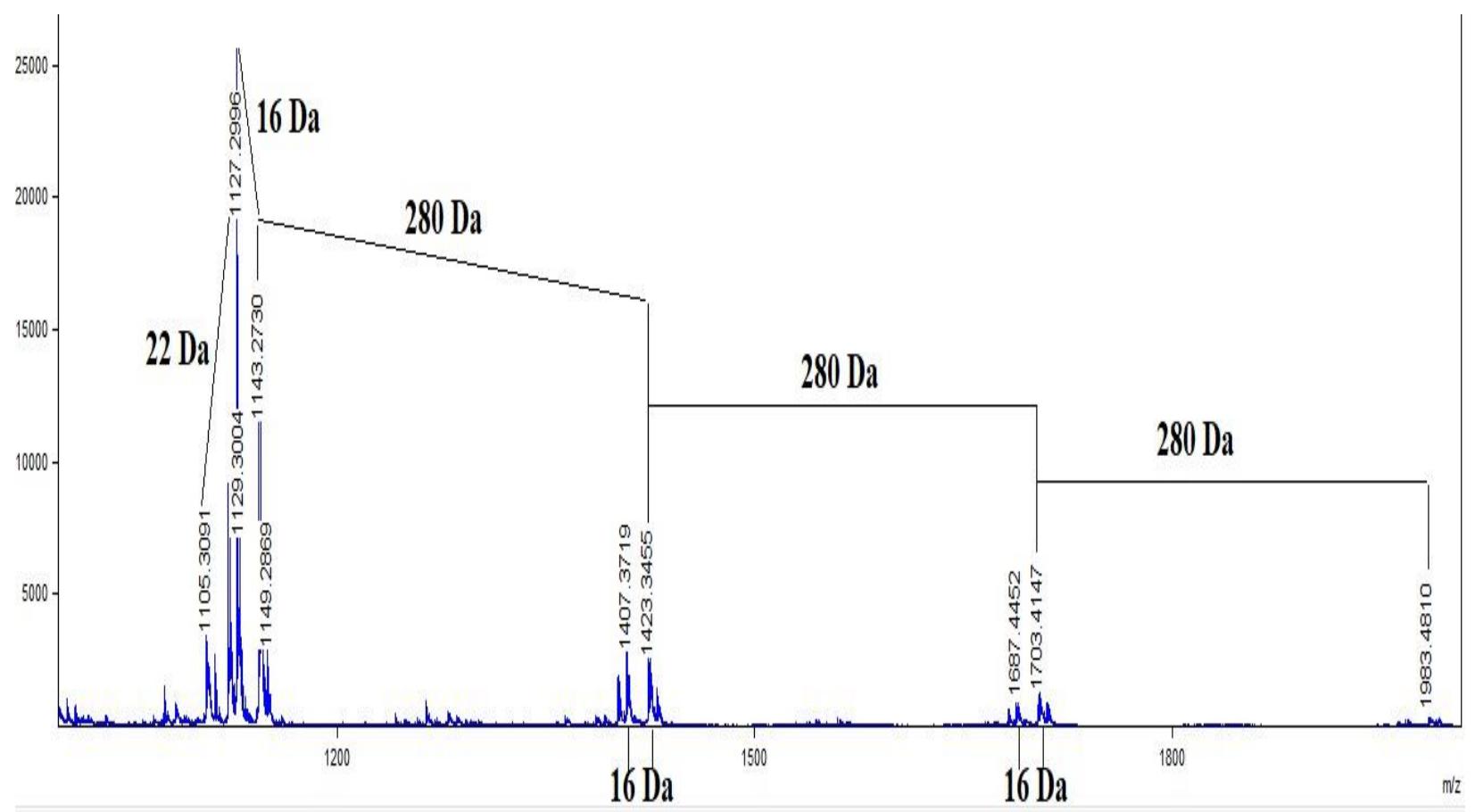

Figure 4: MALDI-TOF-MS (+ ion mode) using HABA as a matrix and displaying the presence of a repeating unit of $280 \mathrm{Da}$ 


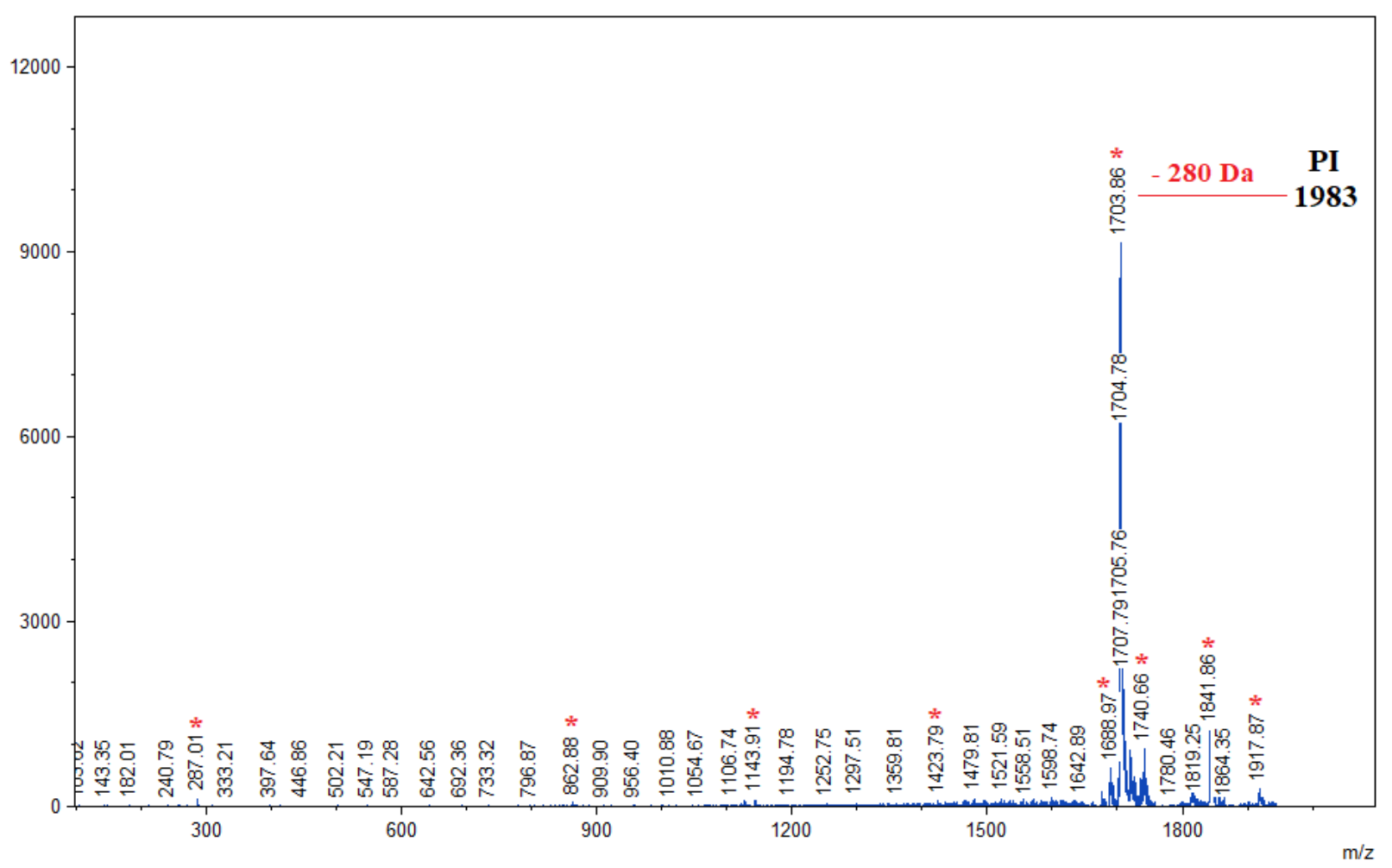

Figure 5a. Product ion scan of the precursor ion at m/z 1983 showing a loss of 280 Da to produce the base peak at $\mathrm{m} / \mathrm{z} 1703$

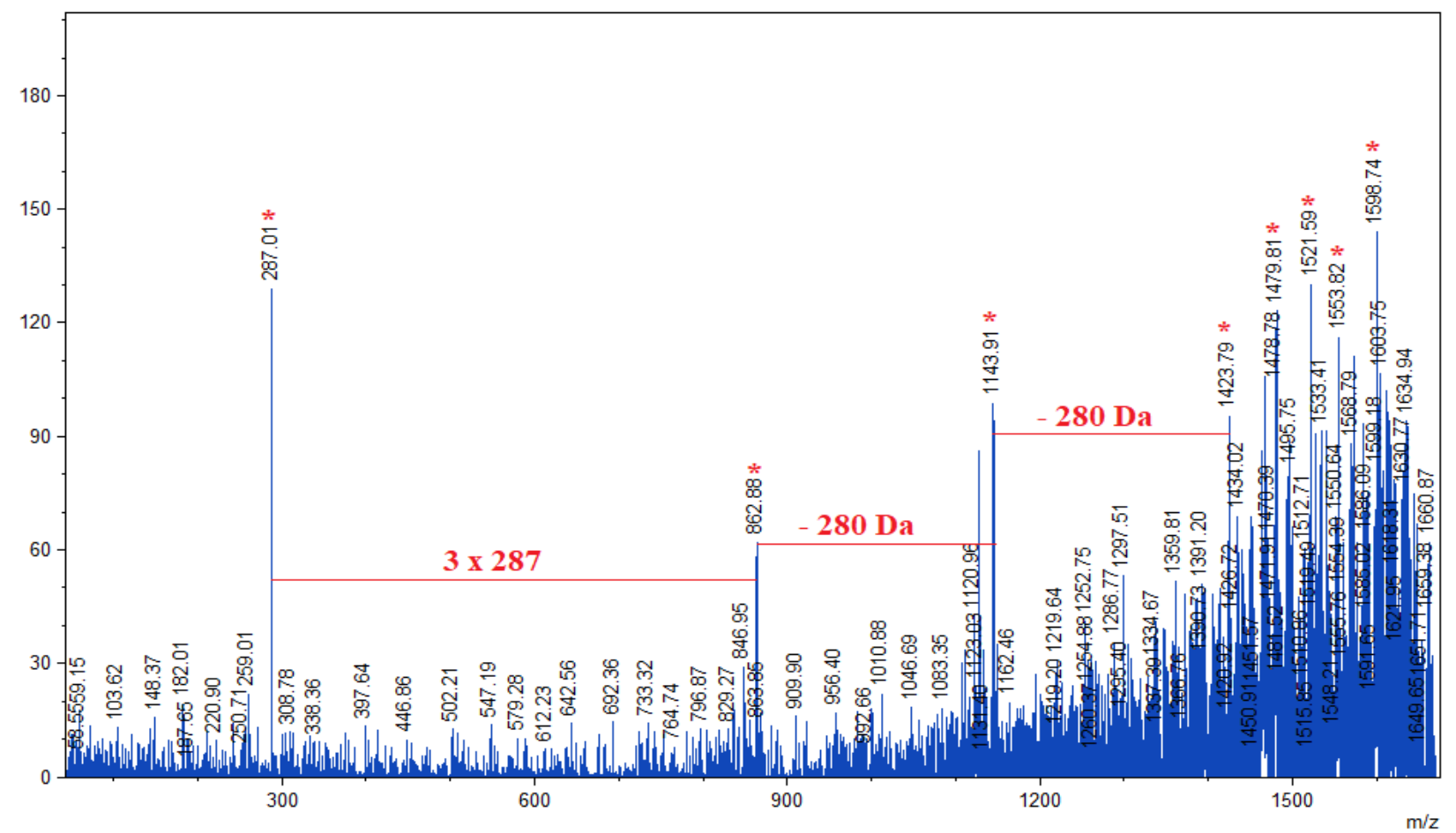

Figure $5 \mathrm{~b}$. Zooming of the low mass region in the product ion scan of the precursor ion at $\mathrm{m} / \mathrm{z}$ 1983 


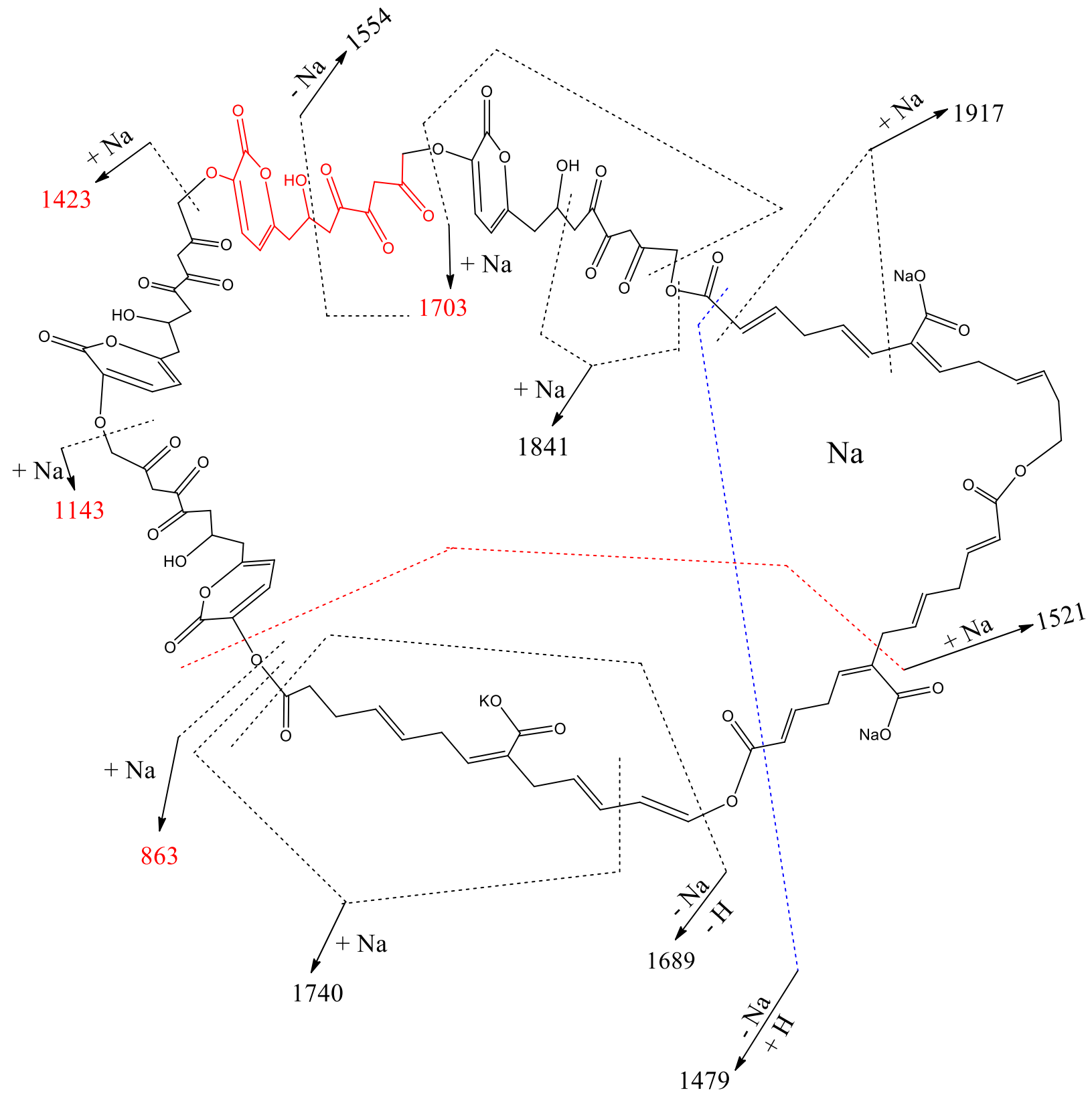

Scheme 2: Fragmentation pattern of the precursor ion at $\mathrm{m} / \mathrm{z}$ 1983. The red part of the molecule represents the repeating unit of $280 \mathrm{Da}$. 


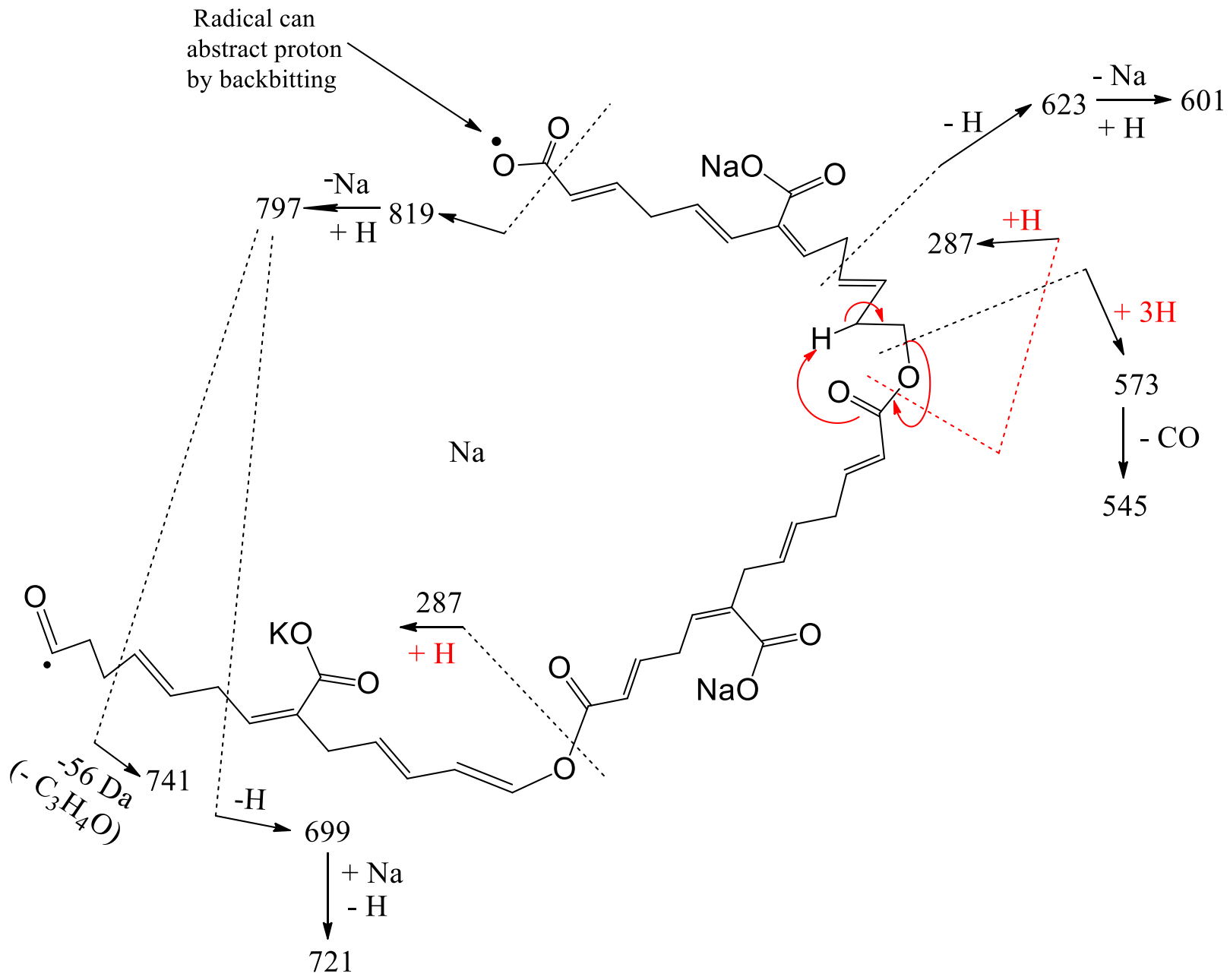

Scheme 3: High-Energy CID-MS/MS fragmentation patterns of Quasi-MS ${ }^{3}$ of the product ion at $\mathrm{m} / \mathrm{z}$ 863. Note: Intramolecular hydrogen transfers in some fragments can occur by backbiting, ${ }^{[39],}$ and Mclafferty rearrangement from the alcohol side, as indicated by red arrows. ${ }^{[40,41]}$ 


\section{Sporopollenin ${ }^{1} \mathrm{H}$ - and ${ }^{13} \mathrm{C}-\mathrm{NMR}, 2 \mathrm{D}{ }^{1} \mathrm{H}-{ }^{1} \mathrm{H}$ NOESY, Rotor-synchronized ${ }^{13} \mathrm{C}\left\{{ }^{1} \mathrm{H}\right\}$ HSQC, and ${ }^{13} \mathrm{C}\left\{{ }^{1} \mathrm{H}\right\}$ multi CP-MAS NMR}

Before starting this section, we would like the readers to recap that the solid-state ${ }^{13} \mathrm{C}-\mathrm{NMR}$ study of the sporopollenin exine appears like the one obtained by $\mathrm{Li}$ et al. for the pine sporopollenin. ${ }^{[15] .}$

The standard ${ }^{1} \mathrm{H}$ spectrum of sporopollenin shows both sharp and broad peaks indicative of a mixture "liquid-like" or more crystalline phase (green line) and a more amorphous phase (pink line) (SI-Figure 10a). Using a CPMG filter, we can easily remove the amorphous phase and observe only the liquid-like structure (SI-Figure 10b). The "liquid-like phase indicates the presence of a mobile sub-structure, such as long fatty acid chains.

After a vigorous search in literature, we were lucky to find a great similarity between the proton NMR spectrum of the "liquid-like" phase of our sporopollenin with that of the ${ }^{1} \mathrm{H}-\mathrm{NMR}$ spectrum of whole seeds of Lesquerella lyrate that contain lipids (SI-Figure 11 a \& b). ${ }^{[42]}$ The two spectra are almost identical; nonetheless, in sporopollenin, two important peaks were absent. The first peak is at $3.5 \mathrm{ppm}$ characteristic for hydroxy fatty acid (- $\mathrm{CHOH}-)$ indicating that $\mathrm{OH}$ is present on a double bond (vinylic), and the peak at $4.8 \mathrm{ppm}$ characteristic for TAG Estolides (branched ester bond). This supports that our hydroxycarboxylic acids are connected linearly. The amorphous part appears to indicate the presence of a more rigid sub-structure containing alpha-pyrone rings (broad peak at $6.79 \mathrm{ppm}$ ) and hydroxylated chains (broad peaks at 3.79 and $0.98 \mathrm{ppm}$ ). These assignments support the presence of polyhydroxylated tetraketide composed of the alpha-pyrone ring and hydroxylated aliphatic chain.

Ten cross signals corresponding to different functional groups were identified from the 2D $\mathrm{H}^{1}-\mathrm{H}^{1}$ NOESY solid state experiments (SI-Figure $12 \mathrm{a} \& \mathrm{~b} \& \mathrm{c} \& \mathrm{~d}$ ). This allowed us to get an idea of the proximity of the proton groups. Whereas, the HSQC (SI-Figure 13 a \& b) indicates the ${ }^{13} \mathrm{C}$ correlation, at least with the most populated groups revealed by $1 \mathrm{D} \mathrm{H}-\mathrm{NMR}$ and $2 \mathrm{D} \mathrm{H}^{1}-\mathrm{H}^{1}$ NOESY. The results are listed in SI-Table 1.

The ${ }^{13} \mathrm{C}\left\{{ }^{1} \mathrm{H}\right\}$ CPMAS NMR confirms the mixture of crystal-like and amorphous characteristics of the sample. Using the multi CP pulse sequence, we can obtain quantitative data within a reasonable timeframe. Deconvolution and integration of the fitted peaks indicate the relative percentage of each group. The results are presented in figure 6 a \& b \& c, Table 1, and SI- 
Table 2. Using the building block obtained from TOF-SIMS and MALDI-MS, we were able to generate a model that is very close to the empirical formula of Lycopodium clavatum sporopollenin and fitted with the quantitative data obtained from C-13 NMR to a large extent (Figure 6 a \& b \& $\mathrm{c}$, and Table1). It should be noted that the weak peak at $\sim 55 \mathrm{ppm}$ is assigned to the methylene group between two ketone groups ( $\beta$-diketone supported by TOF-SIMS-MS/MS), which was left unassigned by Li et al. ${ }^{[15]}$.
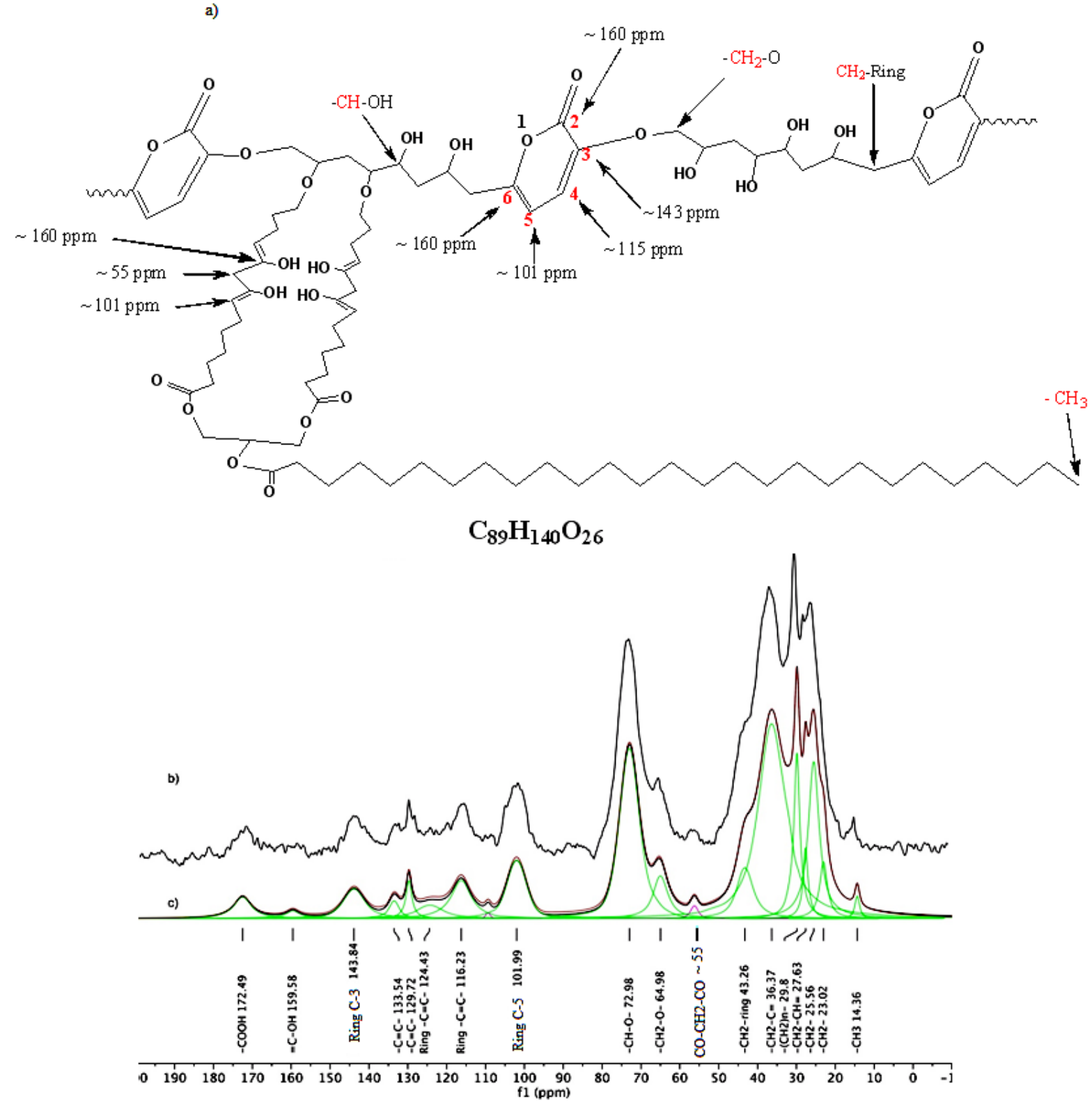

Figure 6: ${ }^{13} \mathrm{C}\left\{{ }^{1} \mathrm{H}\right\}$ multiCP MAS NMR experimental (b) and deconvoluted spectra (c), (a) empirical formula model 


\begin{tabular}{|l|c|c|c|}
\hline \multicolumn{1}{|c|}{ \% of C } & ppm range for & Deconvolution & Model \\
& integration & 2 \\
\hline $\mathrm{CH}_{3}$ (Chain) & $0-20$ & 1 & 58 \\
\hline $\mathrm{CH}_{2}$ (Chain or ring) & $20-50$ & 56 & 3 \\
\hline $\mathrm{O}=\mathrm{C}-\mathrm{CH}_{2}-\mathrm{C}=\mathrm{O}$ & $50-60$ & 2 & 16 \\
\hline $\mathrm{CH}_{2}-\mathrm{O}$ or $\mathrm{CH}-\mathrm{O}$ (Chain) & $60-90$ & 19 & 3 \\
\hline Ring $\mathrm{C}_{5}$ or Chain $\mathrm{C}=\mathrm{C}-\mathrm{O}$ & $90-110$ & 6 & 6 \\
\hline Ring $\mathrm{C}_{4}$ or $\mathrm{C}=\mathrm{C}-\mathrm{CH}_{2}-\mathrm{C}=\mathrm{C}$ & $110-130$ & 8 & 2 \\
\hline $\mathrm{C}=\mathrm{C}$ (Chain) & $130-140$ & 2 & 3 \\
\hline Ring $\mathrm{C}_{3}$ & $140-150$ & 3 & 5 \\
\hline$=\mathrm{C}-\mathrm{OH}$ or Ring $\mathrm{C}_{2}$ or Ring $\mathrm{C}_{6}$ & $150-165$ & 1 & 2 \\
\hline $\mathrm{COOH}$ (Chain) & $165-185$ & 2 & \\
\hline
\end{tabular}

Table 1: Distribution of Carbons in the structure according to deconvolution of the experimental spectrum and Lycopodium clavatum empirical formula model designed according to moieties identified using MS.

\section{High-Resolution X-ray Photoelectron Spectroscopy (HR-XPS)}

The HR-XPS C(1s) surface analysis of sporopollenin (figure 7) showed the main types of linked carbons atoms in the Lycopodium clavatum sporopollenin with their percentage in the sample according to the area calculated under each peak. Most importantly, it showed the complete absence of any satellite peak at higher binding energy that results from the $\pi-\pi *$ transition. It should be noted that the absence of this "shake-up line" dismisses the presence of aromatic compounds and support the absence of aromaticity in the sporopollenin. ${ }^{[43]}$

The solid-state proton NMR of lycopodium clavatum sporopollenin exine showed two types of spectra that accounts for the two components identified by MALDI-TOF-MS and MS/MS analyses. The sharp ${ }^{1} \mathrm{H}-\mathrm{NMR}$ spectrum represents the poly(hydroxyacid) network, while the broad spectrum seems to account for the presence of an aromatic component in the sporopollenin. However, high- resolution X-ray photoelectron spectroscopy (XPS) showed the complete absence of aromaticity in sporopollenin. This supports that this broad proton NMR spectrum accounts for 
the alpha pyrone ring in the polyketide component of sporopollenin. Please bear in mind that the $\alpha$-pyrone rings possess weak aromatic characters, as they can undergo some reactions such as ringopening, Diels-Alder reactions, and electrophilic additions. ${ }^{[44]}$ Fortunately, the $\alpha$-pyrone ring is not a typical aromatic compound, and for this reason, it does not contradict the absence of aromaticity in the sporopollenin revealed by the XPS.

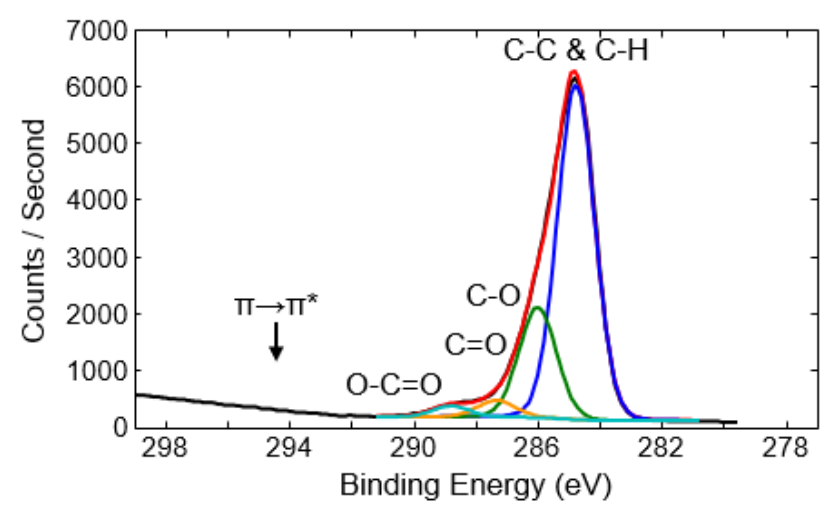

\begin{tabular}{|l|r|r|}
\hline \multicolumn{1}{|c|}{$\begin{array}{c}\text { C 1s } \\
\text { functionality }\end{array}$} & peak BE (eV) & $\begin{array}{r}\text { rel. abundance } \\
(\%)\end{array}$ \\
\hline C-C \& C-H & 284.8 & 71 \\
\hline $\mathrm{C}-\mathrm{O}$ & 286.0 & 23 \\
\hline $\mathrm{C}=\mathrm{O}$ & 287.3 & 4 \\
\hline $\mathrm{O}-\mathrm{C}=\mathrm{O}$ & 288.0 & 2 \\
\hline$\Pi \rightarrow \Pi^{*}$ & N/A & 0 \\
\hline
\end{tabular}

Figure 7: Lycopodium Clavatum Sporopollenin X-ray photoelectron spectroscopy of carbon (1s)

\section{Sporopollenin Model}

To correlate this data to the real scanning electron microscope images (SEM) images of different sporopollenin exines, we used the identified building blocks in this manuscript to build a general model for the formation of the sporopollenin exine that looks like its various network SEM images. For example, Passiflora sp. (Passifloraceae) sporopollenin SEM image is shown in SIfigure 14, showing a circular aperture with a cross-linked network built on it. ${ }^{[45]}$ Although passiflora sp. is a different type of sporopollenin than the one of lycopodium clavatum, its SEM image makes sense with the building units identified in this manuscript (circular polymer and Dendrimer-like network) and help in better visualization of how these units may be connected together. This may provide a clearer view of our model for the sporopollenin exine consists of a circular polymer composed of the polyhydroxylated tetraketide monomers, which contain hydroxyl groups. The circular polymer hydroxyl groups can be attached to poly(hydroxyacid) network chains (dendrimer-like network) through ether bonds. (SI-figure 15). 


\section{CONCLUSION}

Although there have been a lot of contradictions about the structural constituents and the molecular identity of the biopolymer sporopollenin, many scientists around the world focused only on the biomedical applications of sporopollenin, as a drug delivery system, without caring or giving credence to its molecular structure.

Until recently, the sporopollenin exine was described as a highly resistant biopolymer, which was thought to be composed of aromatics, phenolics, and long-chain aliphatic acids. ${ }^{[46,47]}$

In this Manuscript, we have proven by XPS analysis the total absence of aromaticity in the sporopollenin exine. We also have confirmed for the first time the presence of two main sporopollenin building units using solid-state ${ }^{1} \mathrm{H}$ - and ${ }^{13} \mathrm{C}-\mathrm{NMR}, 2 \mathrm{D}^{1} \mathrm{H}-{ }^{1} \mathrm{H}$, and $2 \mathrm{D}{ }^{13} \mathrm{C}-{ }^{1} \mathrm{H}$ NMR experiments, SIMS-TOF-MS, MALDI-TOF-MS, and CID-MS/MS. These analyses indicated the presence of the circular polyhydroxylated tetraketides polymer that represent the main circular rigid backbone of the sporopollenin biopolymer. This latter polymer can be covalently attached by ether links to the poly(hydroxyacid) chain network to form the sporopollenin biopolymer. Also, as mentioned in the introduction section, sporopollenin exine could exist as a spherical dendrimer, which is a typical type of microcapsule used for drug delivery applications. ${ }^{[48]}$

It is quite interesting to mention that it was due to the SIMS-TOF-MS and KeV CIDMS/MS analyses by which we initially discovered the chemistries present on the outermost surfaces of the sporopollenin exine through the discovery of ions characteristic for diacylglycerol (DAG). This led to MALDI-TOF-MS and CID-TOF/TOF-MS/MS analyses that allowed us to cover each constituent of the sporopollenin repeating units. In this context, it should be noted that the use of different matrices helped. The use of 1,5-diaminonaphthalene (DAN) and $\alpha$-cyano-4hydroxycinnamic acid (CHCA) allowed us to obtain a complete characterization of the complex network of the poly(hydroxyacid). Finally, the use of the 2-(4-Hydroxyphenylazo)benzoic acid (HABA) allowed us to establish the presence of the circular polyhydroxylated tetraketide polymer (rigid backbone).

In this manuscript, we were capable of revealing the novel molecular structure of the main framework of the spherical sporpollenin exine. Nevertheless, the exact biosynthesis of sporopollenin is now left to the expert biologists, which hopefully could decipher the exact 
biosynthesis of sporopollenin, especially that today, the regulation genes of sporopollenin biosynthesis have been discovered. ${ }^{[49]}$

In conclusion, we can state that specifically, sporopollenin exine of lycopodium clavatum does not contain any aromatics and bear no resemblance to lignin. Also, for the records, it should be noted that in 1966, Gordon Shaw, one of the earliest pioneers in sporopollenin, withdraw his proposal that sporopollenin exine contains lignin because it does not give any positive test for lignins. ${ }^{[50]}$ Based on our data presented here, we can develop a new and well experimentally proven opinion that sporopollenin exine is composed of aliphatic biopolymer with pseudo aromatic alphapyrone rings presented in the polyhydroxylated tertaketide component of sporopollenin.

Our future work will focus on using different matrices in the MALDI-TOF-MS/MS in the positive or the negative ion mode, which may reveal other diagnostic structural details of the Lycopodium clavatum sporopollenin. Moreover, we will try to investigate the structure of other sporopollenin species by using the same characterization techniques presented here.

\section{Experimental}

\section{Sporopollenin extraction}

The sporopollenin exine used in this manuscript was provided by Prof. Mackenzie group from Hull University, UK. It was prepared as described: L. clavatum L. (club moss) spores were purchased from Tibrewala International (Nepal), acetone from Aldrich UK, and potassium hydroxide, ethanol, orthophosphoric acid, hydrochloric acid, and sodium hydroxide from Fisher Scientific UK Ltd. Sporopollenin exine capsules (SECs) were extracted from L. clavatum L. Spores as follows. Spores (300 g) were stirred in acetone $(900 \mathrm{~mL})$ under reflux for $4 \mathrm{~h}$, filtered, and dried overnight in open air. They were stirred under reflux for $12 \mathrm{~h}$ in an aqueous solution of potassium hydroxide (54 $\mathrm{g}$ in $900 \mathrm{~mL}$ ), the solution being renewed after $6 \mathrm{~h}$, filtered, washed with hot water $(5 \times 300 \mathrm{~mL})$ and hot ethanol $(5 \times 300 \mathrm{~mL})$, and dried overnight in open air. The particles were stirred under reflux for 7 days in orthophosphoric acid $(900 \mathrm{~mL})$, filtered, washed with water (5 x $300 \mathrm{~mL}$ ), acetone, $2 \mathrm{~mol} / \mathrm{L}$ hydrochloric acid, $2 \mathrm{~mol} / \mathrm{L}$ sodium hydroxide (each $300 \mathrm{~mL}$ ), water $(5 \times 300 \mathrm{~mL})$, acetone and ethanol (each $300 \mathrm{~mL})$, and dried at $60{ }^{\circ} \mathrm{C}$ until constant weight (90 $\mathrm{g}$ which account for mass loss of $70 \%$ of the total mass of spores). Elemental analysis of 
sporopollenin (g/100 g) was: carbon 68.90, hydrogen 7.90, nitrogen 0.00 , as determined on a Fisons Instruments Carlo Erba EA 100 C H N S analyzer ${ }^{[51]}$

\section{High-Resolution X-ray Photoelectron Spectrometry (HR-XPS).}

XPS surface analysis was carried out using a PHI VersaProbe III instrument (Physical Electronics, Minnesota, USA) equipped with a monochromated Al $\mathrm{K}_{\alpha}$ X-ray source (hv = 1486.6 $\mathrm{eV})$ and dual-beam charge neutralization comprised of low energy electrons $(\leq 25 \mathrm{eV})$ and low energy $\mathrm{Ar}^{+}$ions $(\leq 10 \mathrm{eV})$. The power of the $\mathrm{x}$-ray beam was set to $24.6 \mathrm{~W}$ with a $100 \mu \mathrm{m}$ beam diameter, and all analyses were performed with a $45^{\circ}$ take-off angle. The hemispherical analyzer was set to a pass energy of $224 \mathrm{eV}$ for survey scans, and $26.0 \mathrm{eV}$ for high resolution scans with $1.0 \mathrm{eV} / \mathrm{step}$ and $0.1 \mathrm{eV} / \mathrm{step}$, respectively; the energy scale was calibrated with reference to the $\mathrm{C}$ 1s peak at a binding energy $(\mathrm{BE})$ of $284.8 \mathrm{eV}(\mathrm{C}-\mathrm{C}, \mathrm{C}-\mathrm{H})$. Peak fittings were performed using a Shirley-type background and a Gaussian-Lorentzian peak fit function with $85 \%$ Gaussian line shape. The high-resolution spectra were smoothed using a 3-point Savitzky Golay function. The chemical species corresponding to each binding energy were attributed using standard materials and the PHI XPS Handbook; quantification was accomplished using Scofield sensitivity factors. Data acquisition was accomplished using PHI SmartSoft-XPS software, and data processing was performed using PHI MultiPak (Physical Electronics, Minnesota, USA) software.

\section{TOF-SIMS and High-Energy KeV CID-MS/MS}

TOF-SIMS tandem MS imaging analysis was performed using a PHI nanoTOF II Parallel Imaging MS/MS instrument (Physical Electronics, Minnesota, USA). A detailed description of this TOFTOF instrument has been reported previously, including the attained spatial resolution, monoisotopic precursor selection, and kilo electron volt collision-induced dissociation (keV-CID) of the selected precursor ions to generate the tandem MS product ion spectra ${ }^{[52-54]}$ The elements and qualities of the tandem MS spectra for composition analysis and structure elucidation have been further elaborated in other reports ${ }^{[55,56]}$ In the present study, all the spectra and images were recorded with electrodynamically bunched pulses of a $30 \mathrm{keV} \mathrm{Bi3}+$ primary ion beam of which the DC current was measured to be $\approx 9 \mathrm{nA}$. The ion beam was operated in the high resolutionsquared (HR2) mode to achieve $<500 \mathrm{~nm}$ lateral resolution at high mass resolving power and without the use of delayed extraction. The field-of-view of each analytical area was either $400 \mu \mathrm{m}$ 
$\times 400 \mu \mathrm{m}$ or $200 \mu \mathrm{m} \times 200 \mu \mathrm{m}$ divided by $256 \times 256$ image pixels. TOF-SIMS tandem MS imaging data were acquired from the samples, held nominally at room temperature, over a range of $\mathrm{m} / \mathrm{z} 0$ 2,000 . The samples were prepared by placing spore powder onto double-sided tape, lightly tapped to remove excess powder, and then blown with clean and dry nitrogen gas to remove loosely bound spores. While potential surface contamination moieties were observed, no pre-sputter was used. The ion fluence for each tandem MS analysis at m/z 253, 255, and $281(\leq 2.50 \times 1012 \mathrm{Bi} 3+/ \mathrm{cm} 2)$ was below the static limit of analysis. While the cumulative dose in this analysis area exceeded the static limit, there was no observed degradation of the precursor ion signal. The ion fluence for each tandem MS analysis at m/z 575 and 603 was $1.41 \times 1013 \mathrm{Bi} 3+/ \mathrm{cm} 2$ and $1.99 \times 1013$ $\mathrm{Bi} 3+/ \mathrm{cm} 2$, respectively.

Nevertheless, degradation of the precursor ion signals was not observed over the course of both analyses at the same location of the sample. During analysis, low energy electrons $(\leq 25 \mathrm{eV})$ and low energy Ar+ ions $(\leq 10 \mathrm{eV})$ were applied for charge compensation. Data acquisition was accomplished using PHI SmartSoft-TOF software, and data processing was performed using PHI TOF-DR (Physical Electronics, MN) software.

\section{MALDI-TOF-MS and High-Energy CID (1KeV) MS/MS}

Prior to MALDI mass spectrometric analysis, the Sporopollenin sample was washed three times using LCMS water (Millipore Sigma) by mixing at $1800 \mathrm{rpm}$ for 45 minutes, followed by the removal of the supernatant.

MALDI matrices $\alpha$-cyano-4-hydroxycinnamic acid (CHCA), 2-(4Hydroxyphenylazo)benzoic acid (HABA), and 1,5-Diaminonaphthalene (DAN) (all obtained from Sigma-Aldrich) were prepared as $10 \mathrm{~g} / \mathrm{L}$ in ethanol: acetonitrile at $1: 1$ ratio with or without $0.1 \%$ trifluoroacetic acid (TFA). Each matrix was further mixed with water at 8:1 ratio by volume (matrix: water) to reduce the spreading of the matrix on the hydrophobic plate surface and thus to obtain a thicker matrix layer. The sandwich method was used to spot the matrix and sample onto the MALDI plate. Here, a layer of the matrix was deposited first $(0.5 \mathrm{uL})$ followed by the layer of the sample $(0.5 \mathrm{uL})$. Lastly, the second layer of the matrix $(0.5 \mathrm{uL})$ was deposited.

Mass Spectrometric data were obtained using an AB Sciex 5800 MALDI TOF/TOF System (Framingham, MA, USA). Data acquisition and data processing were respectively done 
using a TOF TOF Series Explorer and Data Explorer (both from AB Sciex). The instrument is equipped with a $349 \mathrm{~nm} \mathrm{Nd:} \mathrm{YLF} \mathrm{OptiBeam} \mathrm{On-Axis} \mathrm{laser,} \mathrm{and} \mathrm{the} \mathrm{laser} \mathrm{pulse} \mathrm{rate} \mathrm{was} 400 \mathrm{~Hz}$. Reflectron positive and negative modes were used for MS acquisitions. Reflectron and MSMS modes were externally calibrated at 50 ppm mass tolerance. Each MS mass spectrum was collected as a sum of 1000 laser shots, while MSMS mass spectra were obtained as a sum of 1500 shots.

\section{Solid-State ${ }^{1} \mathrm{H}$ - and ${ }^{13} \mathrm{C}-\mathrm{NMR}$; 1H-1H NOESY 2D and 2D 1H-13C HSQC}

The spectra were obtained at $298 \mathrm{~K}$ on a Bruker Avance II 600 spectrometer, equipped with an SB Bruker $3.2 \mathrm{~mm}$ MAS triple-tuned probe operating at $600.33 \mathrm{MHz}$ for ${ }^{1} \mathrm{H}$ and $150.97 \mathrm{MHz}$ for ${ }^{13} \mathrm{C}$. Chemical shifts were referenced to tetramethylsilane (TMS) using adamantane as an intermediate standard for ${ }^{13} \mathrm{C}$. Spinning rates are indicated within the figures. ${ }^{1} \mathrm{H}$ spectra were recorded with a regular 90 pulse (zg) as well as with CPMG filter to separate the crystal-like structure from the amorphous signal. ${ }^{13} \mathrm{C}\left\{{ }^{1} \mathrm{H}\right\}$ cross-polarization (CPMAS) spectra were collected with a Hartmann-Hahn match at $62.5 \mathrm{kHz}$ and $100 \mathrm{kHz}{ }^{1} \mathrm{H}$ decoupling, with a contact time of $2 \mathrm{~ms}$, a recycle delay of $2 \mathrm{~s}$ and $15 \mathrm{k}$ scans. To obtain quantitative data within a reasonable time frame, a multiCP pulse sequence was used, ${ }^{[57]}$ with $t_{z}=0.5 \mathrm{~s}$ and $\mathrm{p} 5=200 \mathrm{~ms}$, $\mathrm{ns}=15 \mathrm{k} .{ }^{1} \mathrm{H}-{ }^{1} \mathrm{H}$ NOESY $2 \mathrm{D}$ spectra were recorded for various mixing time $\left(\mathrm{t}_{\mathrm{mix}}=10,50,100\right.$, and $200 \mathrm{~ms}$ ) at a low spinning rate $\mathrm{v}_{\mathrm{r}}=5 \mathrm{kHz}$ with $\mathrm{ns}=8$ scans. $2 \mathrm{D}{ }^{1} \mathrm{H}^{13} \mathrm{C}$ HSQC were recorded at $\mathrm{V}_{\mathrm{r}}=23 \mathrm{kHz}(\mathrm{sw}=152 \mathrm{ppm})$ for $\mathrm{J}=125 \mathrm{~Hz}$ and $\mathrm{J}=170 \mathrm{~Hz}$ with $\mathrm{ns}=32$ scans. Processing, peaks deconvolution, and integration, as well as spectrum prediction, were all performed using MestReNova.

\section{Acknowledgment}

Mr. Abanoub Mikhael would like to acknowledge the Chemistry Department, Memorial University, for his Ph.D. fellowship. The authors are extremely grateful to Physical Electronics, Minnesota, USA, for the help in measuring the High-Resolution X-Ray Photoelectron Spectrometry (HR-XPS) and the TOF-SIMS analyses. 


\section{REFERENCES}

[1] Mackenzie, G., Beckett, S., Atkin, S., Diego-Taboada, A., Pollen and Spore Shells-Nature's Microcapsules. In Microencapsulation in the Food Industry, Academic Press, 2014, 283-297.

[2] Mackenzie, G., Boa, A.N., Diego-Toboada, A., Atkin, S.L., Sathyapalan, T., Sporopollenin, the Least known yet toughest natural biopolymer, Front. Mater., 2015, 2, 66.

[3] Ahlers, F., Bubert, H., Steuernagel, S., and Wiermann, R., The nature of oxygen in sporopollenin from the pollen of Typha angustifolia L., Zeitschrift für Naturforschung C, 2000, 55(3-4), 129-136.

[4] Domínguez, E., Mercado, J.A., Quesada, M.A., Heredia, A., Isolation of intact pollen exine using anhydrous hydrogen fluoride, Grana, 1998, 37(2), 93-96.

[5] Brooks, J., Shaw, G., Chemical structure of the exine of pollen walls and a new function for carotenoids in nature, Nature, 1968, 219(5153), 532-533.

[6] Hayatsu, R., Botto, R. E., McBeth, R. L., Scott, R. G., Winans, R. E., Chemical alteration of a biological polymer" sporopollenin" during coalification: origin, formation, and transformation of the coal maceral sporinite, Energy Fuels, 1988, 2(6), 843-847.

[7] De Leeuw, J.W., Versteegh, G.J.M., Van Bergen, P.F., 2006. Biomacromolecules of algae and plants and their fossil analogues. Plant Ecol. 182, 20-233.

[8] Watson, J.S., Fraser, W.T., Sephton, M.A., 2012. Formation of a polyalkyl macromolecule from the hydrolysable component within sporopollenin during heating/pyrolysis experiments with Lycopodium spores. J. Anal. Appl. Pyrolysis 95, 138-144.

[9] Kim, S.S., Douglas, C.J., 2013. Sporopollenin monomer biosynthesis in Arabidopsis. J.

Plant Biol. 56, 1-6.

[10] Wehling, K., Niester, C., Boon, J. J., Willemse, M. T. M., Wiermann, R., p-Coumaric acida monomer in the sporopollenin skeleton. Planta, 1989, 179(3), 376-380.

[11] DUTTA, S., HARTKOPF-FRÖDER, C., WILKES, H., GREENWOOD, P., LITTKE, R., MANN, U. (2006). THE MOLECULAR COMPOSITION OF SPOROPOLLENIN FROM FOSSIL MEGASPORES AS REVEALED BY MICRO-FTIR AND PYROLYSIS-GC-MS. In 23rd International Meeting on Organic Geochemistry, P88-MO. Devon, UK Torquay.

[12] Sáiz-Jiménez, C., Production of alkylbenzenes and alkylnaphthalenes upon pyrolysis of unsaturated fatty acids. Naturwissenschaften, 1994, 81(10), 451-453.

[13] Conesa, J. A., Font, R., Marcilla, A., \& Garcia, A. N. (1994). Pyrolysis of polyethylene 
in a fluidized bed reactor. Energy \& Fuels, 8(6), 1238-1246.

[14] Nierop, K. G., Versteegh, G. J., Filley, T. R., \& de Leeuw, J. W. (2019). Quantitative analysis of diverse sporomorph-derived sporopollenins. Phytochemistry, 162, 207-215.

[15] Li, F. S., Phyo, P., Jacobowitz, J., Hong, M., Weng, J. K., The molecular structure of plant sporopollenin, Nat. plants, 2019, 5(1), 41-46.

[16] Bernard, S., Benzerara, K., Beyssac, O., Balan, E., Brown Jr, G. E., Evolution of the macromolecular structure of sporopollenin during thermal degradation. Heliyon, 2015, 1(2), e00034.

[17] Stolle, A., Szuppa, T., Leonhardt, S. E., \& Ondruschka, B. (2011). Ball milling in organic synthesis: solutions and challenges. Chemical Society Reviews, 40(5), 2317-232.

[18] Sjöström, E., \& Alén, R. (Eds.). (2013). Analytical methods in wood chemistry, pulping, and papermaking. Springer Science \& Business Media, page 104.

[19] Kim, S. S., Grienenberger, E., Lallemand, B., Colpitts, C. C., Kim, S. Y., de Azevedo Souza, C., Kombrink, E., LAP6/POLYKETIDE SYNTHASE A and LAP5/POLYKETIDE SYNTHASE B encode hydroxyalkyl $\alpha$-pyrone synthases required for pollen development and sporopollenin biosynthesis in Arabidopsis thaliana, Plant Cell, 2010, 22(12), 4045-4066.

[20] Grienenberger, E., Kim, S. S., Lallemand, B., Geoffroy, P., Heintz, D., de Azevedo Souza, C., Legrand, M., Analysis of TETRAKETIDE $\alpha$-PYRONE REDUCTASE function in Arabidopsis thaliana reveals a previously unknown, but conserved, biochemical pathway in sporopollenin monomer biosynthesis, Plant Cell, 2010, 22(12), 4067-4083.

[21] Nick, P., Opatrny, Z., (Eds.), Applied plant cell biology: cellular tools and approaches for plant biotechnology, springer science and business media, 2014, Vol.22.

[22] Fraser, W. T., Lomax, B. H., Jardine, P. E., Gosling, W. D., \& Sephton, M. A. (2014).

Pollen and spores as a passive monitor of ultraviolet radiation. Frontiers in Ecology and Evolution, 2, 12.

[23] Chu, M., Mierzwa, R., Xu, L., He, L., Terracciano, J., Patel, M., ... \& Chan, T. M. (2002). Structure of Sch 419560, a novel $\alpha$-pyrone antibiotic produced by Pseudomonas fluorescens. The Journal of antibiotics, 55(2), 215-218.

[24] Zetzsche, F., and Kälin, O., Untersuchungen über die membrane der sporen und pollen v. 4. Zur autoxidation der sporopollenine, Helv. Chim.Acta., 1931, 14(1), 517-519. 
[25] Gonzalez-Cruz, P., Uddin, M. J., Atwe, S. U., Abidi, N., \& Gill, H. S. (2018). Chemical treatment method for obtaining clean and intact pollen shells of different species. ACS biomaterials science \& engineering, 4(7), 2319-2329.

[26] Barrier, S. (2008). Physical and chemical properties of sporopollenin exine particles (Doctoral dissertation, University of Hull).

[27] Gilli, G., Bertolasi, V., Ferretti, V., \& Gilli, P. (1993). Resonance-assisted hydrogen bonding. III. Formation of intermolecular hydrogen-bonded chains in crystals of $\beta$-diketone enols and its relevance to molecular association. Acta Crystallographica Section B: Structural Science, 49(3), 564-576.

[28] Pan, M. H., Huang, T. M., \& Lin, J. K. (1999). Biotransformation of curcumin through reduction and glucuronidation in mice. Drug metabolism and disposition, 27(4), 486-494.

[29] Wesdemiotis, C., Solak, N., Polce, M. J., Dabney, D. E., Chaicharoen, K., \& Katzenmeyer, B. C. (2011). Fragmentation pathways of polymer ions. Mass spectrometry reviews, 30(4), 523559 .

[30] Francke, W., Lübke, G., Schröder, W., Reckziegel, A., Imperatriz-Fonseca, V., Kleinert, A., Engels, W. (2000). Identification of oxygen containing volatiles in cephalic secretions of workers of Brazilian stingless bees. Journal of the Brazilian Chemical Society, 11(6), 562-571.

[31] Tengö, J., Groth, I., Bergström, G., Schröder, W., Krohn, S., \& Francke, W. (1985). Volatile secretions in three species of Dufourea (Hymenoptera: Halictidae) bees: chemical composition and phylogeny. Zeitschrift für Naturforschung C, 40(9-10), 657-660.

[32] Thomas, A., Charbonneau, J. L., Fournaise, E., \& Chaurand, P. (2012). Sublimation of new matrix candidates for high spatial resolution imaging mass spectrometry of lipids: enhanced information in both positive and negative polarities after 1, 5-diaminonapthalene deposition. Analytical chemistry, 84(4), 2048-2054. 
[33] Hughey, C. A., Hendrickson, C. L., Rodgers, R. P., Marshall, A. G., \& Qian, K. (2001). Kendrick mass defect spectrum: a compact visual analysis for ultrahigh-resolution broadband mass spectra. Analytical Chemistry, 73(19), 4676-4681.

[34] Sugiyama, Y., Kawakishi, S., \& Osawa, T. (1996). Involvement of the $\beta$-diketone moiety in the antioxidative mechanism of tetrahydrocurcumin. Biochemical pharmacology, 52(4), 519-525.

[35] Kretzmann, J. A., Evans, C. W., Norret, M., \& Iyer, K. S. (2017). Supramolecular assemblies of dendrimers and dendritic polymers in nanomedicine. In Comprehensive Supramolecular Chemistry II (pp. 237-256). Academic Press (Elsevier Inc.)

[36] Murphy, R. C. (2014). Tandem mass spectrometry of lipids: molecular analysis of complex lipids. Royal Society of Chemistry.

[37] Neubert, H., Halket, J. M., Ocana, M. F., \& Patel, R. K. (2004). MALDI post-source decay and LIFT-TOF/TOF investigation of $\alpha$-cyano-4-hydroxycinnamic acid cluster interferences. Journal of the American Society for Mass Spectrometry, 15(3), 336-343.

[38] Uddin, M. J., Abidi, N., Warzywoda, J., \& Gill, H. S. (2019). Investigation of the fate of proteins and hydrophilicity/hydrophobicity of Lycopodium clavatum spores after organic solventbase-acid treatment. ACS applied materials \& interfaces.

[39] Raska, C. S., Parker, C. E., Huang, C., Han, J., Glish, G. L., Pope, M., \& Borchers, C. H. (2002). Pseudo-MS ${ }^{3}$ in a MALDI orthogonal quadrupole-time of flight mass spectrometer. Journal of the American Society for Mass Spectrometry, 13(9), 1034-1041.

[40] Banoub, J. H., Demian, W. L., Piazzetta, P., Sarkis, G., Kanawati, B., Lafont, D., Fridgen, T. D. (2015). The in situ gas-phase formation of a C-glycoside ion obtained during electrospray ionization tandem mass spectrometry. A unique intramolecular mechanism involving an ionmolecule reaction. Rapid Communications in Mass Spectrometry, 29(19), 1717-1732.

[41] Joly, N., Aneed, A. E., Martin, P., Cecchelli, R., \& Banoub, J. (2005). Structural determination of the novel fragmentation routes of morphine opiate receptor antagonists using electrospray ionization quadrupole time-of-flight tandem mass spectrometry. Rapid Communications in Mass Spectrometry, 19(21), 3119-3130. 
[42] Zhang, H., Olson, D. J., Van, D., Purves, R. W., \& Smith, M. A. (2012). Rapid identification of triacylglycerol-estolides in plant and fungal oils. Industrial Crops and Products, 37(1), 186-194.

[43] Moulder, J. F. (1992). Handbook of X-ray photoelectron spectroscopy. Physical electronics

[44] Joule, J. A., \& Mills, K., Heterocyclic Chemistry, John Wiley and Sons, 2010

[45] Wang, R., \& Dobritsa, A. A. (2018). Exine and aperture patterns on the pollen surface: Their formation and roles in plant reproduction. Annual Plant Reviews, JA Roberts, ed (John Wiley \& Sons), 1-40.

[46] Piffanelli P, Ross JHE, Murphy DJ (1998) Biogenesis and function of the lipidic structures of pollen grains. Sex Plant Reprod 11:65-80

[47] Ariizumi T, Toriyama K (2011) Genetic regulation of sporopollenin synthesis and pollen exine development. Annu Rev Plant Biol 62:437-460

[48] Gillies, E. R., \& Frechet, J. M. (2005). Dendrimers and dendritic polymers in drug delivery. Drug discovery today, 10(1), 35-43.

[49] Wang, K., Guo, Z. L., Zhou, W. T., Zhang, C., Zhang, Z. Y., Lou, Y., Yang, Z. N. (2018). The regulation of sporopollenin biosynthesis genes for rapid pollen wall formation. Plant physiology, 178(1), 283-294.

[50] J. Brooks \& G. Shaw (1968) The Post-Tetrad Ontogeny of the Pollen Wall and the Chemical Structure of the Sporopollenin of Lilium Henryi, Grana, 8:2-3, 227-234.

[51] Barrier, S., Diego-Taboada, A., Thomasson, M. J., Madden, L., Pointon, J. C., Wadhawan, J. D., ... \& Mackenzie, G. (2011). Viability of plant spore exine capsules for microencapsulation. Journal of Materials Chemistry, 21(4), 975-981.

[52] Fisher, G. L.; Bruinen, A. L.; Ogrinc Potocnik, N.; Hammond, J. S.; Bryan, S. R.; Larson, P. E.; Heeren, R. M., A New Method and Mass Spectrometer Design for TOF-SIMS Parallel Imaging MS/MS. Anal. Chem. 2016, 88, 6433-6440. 
[53] Fisher, G. L.; Hammond, J. S.; Bryan, S. R.; Larson, P. E.; Heeren, R. M. A., The Composition of Poly(Ethylene Terephthalate) (PET) Surface Precipitates Determined at High Resolving Power by Tandem Mass Spectrometry Imaging. Microsc. Microanal. 2017, 23, 843-848.

[54] Chini, C. E.; Fisher, G. L.; Johnson, B.; Tamkun, M. M.; Kraft, M. L., Observation of Endoplasmic Reticulum Tubules via TOF-SIMS Tandem Mass Spectrometry Imaging of Transfected Cells. Biointerph. 2018, 13, 03B409.

[55] Fu, T.; Touboul, D.; Della-Negra, S.; Houël, E.; Amusant, N.; Duplais, C.; Fisher, G.L.; Brunelle, A., Tandem MS Imaging and In Situ Characterization of Bioactive Wood Metabolites in Amazonian Tree Species Sextonia rubra. Anal. Chem. 2018, 90, 7535-7543. [56] Fu, T.; Houël, E.; Amusant, N.; Touboul, D.; Genta-Jouve, G.; Della-Negra, S.; Fisher, G.L.; Brunelle, A.; Duplais, C., Biosynthetic Investigation of $\gamma$-Lactones in Sextonia rubra Wood Using In Situ TOF-SIMS MS/MS Imaging to Localize and Characterize Biosynthetic Intermediates. Nat. Sci. Rep. 2019, 9, 1928-1938.

[57] Johnson, R. L., \& Schmidt-Rohr, K. (2014). Quantitative solid-state 13C NMR with signal enhancement by multiple cross polarization. Journal of Magnetic Resonance, 239, 44-49. 